\title{
Component-Specific versus Comprehensive Habits in a Model of Income and Consumption Taxation.
}

\author{
Constantin T. Gurdgiev \\ Department of Economics \\ The Policy Institute \\ Trinity College, Dublin
}

gurdgiec@tcd.ie

December 2004.

\begin{abstract}
.
This paper proposes a model of economy with weakly non-separable preferences for both work effort and consumption. Households who derive utility from consumption of a single commodity and leisure take into account the habitual dependency of their utility on both labour supply and consumption in the past. As a result, this model provides an analysis of the effects of labour income and consumption taxes increase on asset holdings, consumption and labour supply of households. The model of comprehensive habits is contrasted by the standard habits in consumption model that is extended to include endogenous labour supply decisions. We show that one of the main results of the model includes the possibility for using comprehensive habits to capture the simultaneous time persistency in the behaviour of both consumption and leisure demand. The model also yields interesting results in capturing the possibility for either co-movement or counter-movement of the main choice variables in response to the exogenous tax policy change.
\end{abstract}

Key Words: Habits, Consumption, Leisure, Income Tax

JEL Classification: E10, E21, E62 


\section{Introduction.}

In recent years, we have seen a resurgence of interest in the issue of time-inseparability of consumption. Following empirical research, many macroeconomists have used habit formation as a tool for developing models of consumption and savings behaviour that provided a 'better fit' for the data. In particular, habits were shown to be useful in resolving several major puzzles in macroeconomics.

Alongside the work of Abel (1990), Constantinides (1990) uses habitual inseparability in consumption to resolve the equity premium puzzle in asset price models. Similarly, Gali (1994) resorts to habits in consumption to explain several puzzles with portfolio choice and asset pricing models. Carroll et al (2000) developed a habit formation model to explain the empirically documented reversal of causality between savings and growth relative to the traditional models of economic growth. Earlier, Muellbauer (1988) and Dynan (1992) have shown that habits in consumption are successful in explaining the hump-shaped delayed response of consumption to changes in income. Fuhrer (1999) addresses the role of habits in explaining the excess smoothness puzzles in consumption, inflation and spending. Last, but not least, Carroll (1999) shows that contrary to the traditional permanent income hypothesis, empirically low marginal propensity to consume out of income shocks can be captured by the habits in consumption.

Across the habits literature, the main idea of habit formation remains the same. The habitual consumption stock accumulated over the past history of consumption by a representative agent has a direct effect on consumers' current utility. This may involve either the inward- or the outward-looking habits, as discussed in depth in Carroll et al (2000). The agents may care about the aggregate economy-wide stock of habits (as in the case of outward-looking agents) or only concern themselves with the ratio of their own consumption to their own habits (as in the case of inward-looking habits mechanism). Depending on their type, consumers wish to smooth ether both the level and the growth rate of consumption over time or only the level of their consumption. Hence, in response to an exogenous income shock, consumption will adjust gradually to a new steady state.

The robustness of the theoretical predictions of the habit formation models in consumption to the utility function and the choice of laws of motion specifications is a feature well established in the literature. Mansoorian (1996) shows that under a set of 
general assumptions on the utility function given by Ryder and Heal (1973), a general model of habit formation in consumption will exhibit saddle path stability in steady state solutions. Similar results are shown in Gurdgiev (2003) paper that introduces inwardlooking habits in leisure.

The central feature of the majority of habit formation models in consumption is the ad-hoc nature of labour supply. Following the tradition established by Boyer (1978), the majority of papers on habits in consumption are based on the assumption of inelastic labour supply. As a result, changes in economic policy or other exogenous shocks cannot be discussed in the context of the labour/leisure and the leisure/consumption trade-offs.

On the other hand, a few papers such as Faria (2001) and Graham (2003) discuss the implications of including elastic labour supply considerations into the model with habitual consumption. Faria (2001) looks at the inward-looking habits mechanism in consumption and its effects on leisure in the standard neoclassical growth model. Graham (2003) shows that in dynamic simulations the traditional habit formation models extended to include the endogenous labour supply perform equally poorly with respect to both capturing the persistence of leisure and consumption as the standard RBC models. This result, albeit not discussed analytically, indicates that a new approach to the way we interpret habits is warranted in order to capture the dynamics of endogenous leisure choices.

To the best of our knowledge, no literature currently comprehensively discusses the role of leisure in determining the macroeconomic behaviour of the agents in the presence of habits in consumption and leisure taken either separately or jointly. As argued in Gurdgiev (2003), labour supply exhibits a strong degree of persistence in response to economic shocks. It is a commonly known fact (see for example the discussion in Ehrenberg and Smith (1982), and McConnell and Brue (1995)) that empirical adjustments in labour supply to exogenous income and wage shocks do not follow jump discontinuity dynamics. Instead, leisure demand and labour supply both adjust gradually in response to exogenous shocks. This warrants the approach of the present paper to incorporate directly the habituality of leisure into the household optimisation problem. In broader terms, as pointed out by Becker (1965) and others, leisure may be at least partially inseparable from consumption. Hence, if past consumption patterns are important to the determination of future consumption plans, past leisure choices may also have a direct impact on the responses in leisure to changes in the economic environment. 
The following paper aims to close several important gaps in the habit formation literature. To begin with, we propose a straightforward extension of the habitual consumption model to include explicit consideration of the elastic labour supply decisions by the consumers. Assuming at first that leisure enters the utility function independent of habits, we develop our first model. As expected, time separability of leisure implies that while consumption exhibits a gradual adjustment to income tax change, leisure demand and thus labour supply exhibit jump discontinuity in their adjustment paths. This part of the study, therefore supplies a closed end solution result that confirms Graham (2003) simulated solutions. We treat this model as a benchmark.

In addition to incorporating explicitly labour supply decisions into the standard model of habit formation in consumption, the first model presented below contributes to the literature by providing explicit solutions for the real variables responses to changes in labour income and consumption tax policies. To the best of our knowledge, this discussion is new to the literature on habits in general.

The benchmark model, as shown hereinafter, fails to account for the gradual adjustment in labour supply. Hence we develop a model with habits arising from both consumption and leisure histories of households. We show that, in this model, dynamic responses in both leisure and consumption are linked to each other and to the exogenous economic environment described by the parameters of the model. Implications of these links are discussed in the context of the households' asset holdings, consumption, leisure and habits stock dynamics. The main results of the model with comprehensive habits are further enhanced by the discussion of the effects of tax policy changes on the real variables. Once again, both the model of comprehensive itself and the subsequent discussion of the tax effects in the model are entirely new to the literature.

In addition, to motivate our emphasis on the combined (comprehensive) habits in leisure and consumption we consider two major reasons that, in general, make time-inseparability of consumption and leisure relevant to the issue of taxation. First, time additivity of either one of the components of household choice implies a constant rate of time preferences. As shown in Sen and Turnovsky (1989) this makes the steady state analysis of tax policies extremely sensitive to the initial conditions. One way of solving it is through the introduction of endogenous time preferences, as done, for example, in Shi (1994). Another approach is to introduce habit dependency. Carroll (2000) shows the benefits of the latter 
approach, which implies that along the adjustment path to the new steady state, households' time preferences are not constant but are dependent on the habit formation parameters. Second, in time-separable models, wealth and the substitution effects of the income tax changes cannot be separated. This point is raised in Barro and King (1984). As a result of this, the relative changes in consumption and leisure due to changes in after-tax wage must be equal to the relative response caused by wealth change.

In recent work, Becker, Murphy and Werning (2002) discuss the importance of status, as a separate variable in household optimisation. Our model of 'comprehensive' habitual good closely follows their reasoning with respect to the preferences specification. In the Becker et all (2002) model, status is separate from a consumption good. As such there is a tradeoff across consumption and status in household decisions. This implies that status raises the marginal utility of consumption and of income. In our model, marginal utility of consumption is increasing in habits. Traditional habits in consumption literature explains this by observing that for two agents with identical preferences who differ in their habits stock levels, the agent with the highest habitual reference stock will enjoy greater marginal utility of consumption. In addition to this traditional effect, our model suggests another link between habits and the marginal utility of consumption. By making habits stock dependable on leisure, we establish a complimentarity link between leisure and the marginal utility of consumption that acts in a similar fashion to the idea of status goods.

Another aspect of Becker et al (2002) is that the status good is characterised by a relatively fixed-supply nature. Traditional habit in consumption models do not have a similar feature with regards to habits stock. In our model, habits stock is determined at any period of time by both consumption and leisure. As consumption and leisure may vary in the opposite directions, comprehensive habits stock may not be as flexible as consumption itself. Thus our model of comprehensive habits allows for a closer relationship between habits role as either a reference good or a status good. This is inherent in the distinction between internal and external habits, yet is not directly addressed by consumption habits alone.

This paper is organised as follows. Part 1 develops a model of habits in consumption in the presence of elastic labour supply. This provides a basis for future analysis of the implications of incorporating leisure into the mainstream habit formation models. Part 2 builds on the preceding model to develop a comprehensive model of adjacent 
complementarity in consumption and habits combined with the weak separability of consumption and leisure in preferences. Part 3 concludes the discussion of the two models by comparing various tax effects on the steady state levels of real variables, and by examining the effects of the habit formation parameters on the models predictions.

\section{Part 1. A Model of Leisure Demand in the Presence of Habits in Consumption.}

Following the intuition presented in the Introduction, we develop a representative agent model of habits in consumption in the presence of elastic labour supply. This provides a basis for future analysis of the implications of incorporating leisure into the mainstream habit formation models. As mentioned above, traditional habits in consumption literature assumes inelastic labour supply. As a result of this assumption, along the adjustment path, changes in consumption are associated with no labour-leisure trade-off. Model 1 below introduces explicit analysis of the effects of habits in consumption on dynamics of labour supply and discusses the interactions between labour supply, consumption and foreign asset holdings of the households in response to the exogenous shocks to income (e.g. tax policy changes).

\subsection{General Solution.}

Consider an economy with a single consumption good, $C_{t}$. In labour markets, infinitely lived households face a fixed real wage rate $w$ and supply $1-l_{t}$ units of labour. Labour income is taxed at the rate $\tau_{l}>0$ while consumption is taxed at rate $\tau_{c}>0$. Tax proceeds are rebated in a lump-sum fashion, with tax rebate denoted by $T_{t}$. Let $(1-\tau) w\left(1-l_{t}\right)$ be a given level of labour income after the income tax. We can express the tax revenue rebated by the government as:

$T_{t}=\tau w\left(1-l_{t}\right)+\tau_{c} C_{t}$

As usual, households take $T_{t}$ as exogenously given in the optimisation problem. 
Agents maximise their lifetime utility from leisure and consumption accounting for consumption habits stock:

$U=\int_{0}^{\infty} U\left(C_{i t}, h_{i t} ; l_{i t}\right) e^{-\delta t} d t$

subject to the budget constraint relating agents' holdings of foreign bonds, $B_{t}$, tax payments and transfer receipts $\left(T_{t}\right)$ :

$\dot{B}_{t}=r B_{t}+w\left(1-\tau_{l}\right)\left(1-l_{t}\right)-\left(1+\tau_{c}\right) C_{t}+T_{t}$

In equation (2), we separate consumption and habits stock terms $\left(C_{i t}, h_{i t}\right)$ from the demand for leisure term in order to capture the idea that in Model 1, consumption and leisure are weakly separable in the utility and that habits effects apply to the consumption component of the utility function alone. As mentioned in the introduction above, this model will serve as a benchmark model for future analysis.

Following Ryder and Heal (1973), we assume that:

$U_{C}>0$ and $U_{C C}<0$

$U_{l}>0$, and $U_{l l}<0$

$U_{h}<0$ and $U_{h h}<0$

$U_{h l}=U_{C l}=0$

$U_{h h} U_{C C}-U_{C h}^{2} \geq 0$ (concavity)

$U_{C}+U_{h}>0$

$U_{C h} \geq 0$

The assumptions presented in equation (4) are important in the context of comparing the benchmark model against the following extension. First, these assumptions support the analysis presented in Ryder and Heal (1973) with respect to the existence of a stable steady state. Second, these assumptions with respect to the separability of leisure and consumption parallel Hansen and Wright (1992) and Faria (2001). Finally, the last assumption reflects the arguments presented in both Mansoorian (1993) with respect to the traditional role of habits and in Becker, Murphy and Werning (2000) with respect to the status-like nature of a habitual standard of living. The latter aspect of these assumptions is important to the understanding of the following extension of the 
benchmark model to Model 2 below, the intuition for which is discussed in the Introduction.

Since labour tax payments are rebated in a lump-sum fashion, agents take $T_{t}$ as given. This, in conjunction with the fact that marginal rate of substitution in consumption and leisure in period $t$ are independent of their levels at time $j \neq t$, implies that $U(.,$.$) is$ homothetic. Furthermore, the assumption that the utility function is weakly separable in habits and leisure implies that in our model habits only serve as a reference point for the utility of consumption and do not distort the utility of leisure. This is standard for models with habit formation in consumption. It also implies that preferences specified under equation (4) exhibit the adjacent complementarity property so that a change in the current consumption has the same direction effect on the future marginal utility discounted forward from today.

The assumed additivity of leisure and consumption in preferences can be justified on the following grounds:

- First, using past choices of consumption as a reference point alone without distorting the marginal utility of leisure implies that the strength of habits will affect leisure demand only in so far as labour supply can be used by households to maintain a habitual standard of living in consumption. Thus stronger habits are now needed in order to generate the desired sensitivity of consumption than in the model with exogenous labour supply. This is the point made in the numerical results obtained by Graham (2003).

- Second, in so far as there are no empirical tests of the persistence in leisure at the aggregate and individual levels, separation of consumption habits and demand for leisure eliminates the need for resorting to the arbitrary parameterisation of the model in its leisure component. The problem here is that while there exists extensive literature on acceptable parameterisation of the habits-in-consumption models, little or no empirical guidance currently can be found on parameterisation of the endogenous leisure components. This problem is especially pronounced in the context of the comprehensive habits model, i.e. Model 2 below. In this model, neither the strength of habits-in-leisure in utility parameter, nor parameters on the speed of habits in leisure convergence and the relative weight of leisure in the law of motion for comprehensive habits can be justified empirically. 
- Third, the current specification, once extended to cover leisure in addition to consumption, as shown in Model 2, allows us to reconcile habitual leisure with habits-like behaviour of aggregate consumption and the possibility for lower persistence in individual consumption vis-à-vis leisure.

Prior to considering the dynamic program based on equation (3), we must impose the following transversality conditions. The first condition rules out the possibility of unbounded borrowing by the economy at large. As standard,

$K_{t} \equiv \frac{w l_{t}}{r}+B_{t} \geq 0$

Since the right-hand-side (hereinafter, RHS) of inequality, condition (5) involves both bonds and labour supply, $K_{t}$ is fully endogenous to the decision making by households. Hence, in the following optimisation program we can alternatively consider the budget constraint to be a function of the aggregate resources available to the household, namely $K_{t}$. Mansoorian (1993) takes this approach. However, we restrict our attention to households currently participating in the labour force, so that $1>l_{t}>0$. Under this restriction, optimisation with respect to $K_{t}$ is equivalent to optimising with respect to $B_{t}$ and $l_{t}$. Subsequently we define the current value Hamiltonian in terms of these two variables.

Furthermore, we shall impose terminal conditions that rule out corner solutions for consumption and leisure:

$$
\begin{aligned}
& \lim _{C \rightarrow 0} U_{C}\left(C_{t}, h_{t} ; l_{t}\right)=\lim _{l \rightarrow 0} U_{l}\left(C_{t}, h_{t} ; l_{t}\right)=\infty \\
& \lim _{C \rightarrow 0}\left[U_{C}\left(C, C ; l_{t}\right)+U_{h}\left(C, C ; l_{t}\right)\right]=\infty
\end{aligned}
$$

In equation (3), the utility function depends on both leisure expenditure and stock of habits in consumption $\left(h_{t}\right)$. We assume that agents are endowed with some initial stock of habits $\left(h_{0}\right)$ and that habits stock evolves according to

$$
\dot{h}_{t}=\lambda\left(C_{t}-h_{t}\right)
$$

In so far as $\lambda$ captures the speed of adjustment of habits stock to consumption, setting $\lambda=0$ implies that in our model, habits do not matter (their stock remains static relative to 
consumption demand). As $\lambda \rightarrow 0$, consumption demand decisions of agents are less and less influenced by their initial endowment of habits $\left(h_{0}\right)$. In this case, households will be able to maintain different levels of habits stock and consumption even in the steady state. On the other hand, if $\lambda \rightarrow 1$, agents reach their steady state level of consumption demand nearly instantaneously and their stock of habits has the weakest effect on their consumption demand. Once again, as standard, the ratio of consumption to habits along the steady state path will evolve so that $c_{t} / h_{t} \geq 1$. Thus in the steady state, $(c / h)_{s s}=1$.

The current value Hamiltonian specification for agents is given by:

$$
\begin{aligned}
H_{C V}= & U\left(C_{t}, h_{t} ; l_{t}\right)+ \\
& +\mu_{t}\left[r B_{t}+w\left(1-\tau_{l}\right)\left(1-l_{t}\right)-\left(1+\tau_{c}\right) C_{t}+T_{t}\right]+\xi_{t} \lambda\left(C_{t}-h_{t}\right)
\end{aligned}
$$

Note that equation (7) implies that habits are internal to the household decision-making. An alternative to this assumption is to represent habits by an exogenous reference variable outside the choice variables of the agents. The two alternative specifications are discussed in depth in Carroll, Overland, Weil (1994), as well as in Gurdgiev (2003). However, from equation (7) it is clear that in absence of habits in the optimisation set, the model will be reduced to a single differential equation for asset holdings and the exogenously determined law of motion for aggregate habits stock. In this case, the dynamic multiplier on habits component of the current value Hamiltonian will be always zero. This in turn will mean that the model solutions below will correspond to the case of a stable equilibrium that is qualitatively similar to the results of the model provided hereinafter.

Furthermore, to keep both Models 1 and 2 tractable we omit consideration of the tax on income from the foreign assets held by the households. In part, analysis of this additional source of tax policy can be viewed in the context of interpreting the real interest rate, $r$, as the net-of-tax rate of return. While being interesting in general, tax on income arising from assets is most pertinent in the context of the wealthier households, while consumption and labour income taxes are by far more general in the breadth of their incidence.

Solutions to this model will follow closely along the lines of the methods presented in Mansoorian (1993), with two major exceptions. Mansoorian's (1993) and later models do not include consideration of either income or consumption taxes presented below, or an 
endogenous determination of labour supply. In addition, in contrast with Mansoorian $(1992,1993,1996)$, we solve the model in terms of direct utility function optimisation instead of the two-stage optimisation of an indirect utility function. The technical details of the derivations of the results presented below are relegated to the Appendix 1 for model 1 , and to the Appendix 2 for model 2.

From equation (7), the first order conditions for the optimum are:

$$
\begin{aligned}
& U_{C}=\mu_{t}\left(1+\tau_{c}\right)-\xi_{t} \lambda \\
& -U_{h}+\xi_{t}(\lambda+\delta)=\dot{\xi}_{t} \\
& U_{l}=\mu_{t} w\left(1-\tau_{l}\right) \\
& \dot{\mu}_{t}=\mu_{t}(\delta-r)
\end{aligned}
$$

Clearly, in the steady state, $\dot{\mu}=0$, as long as we assume:

$\delta=r$

In addition to the terminal conditions (5) we impose the following transversaltiy conditions expressed as a function of the model multipliers. To ensure that the economy is on the steady state path, as consistent with conditions in (5), let

$\lim _{t \rightarrow \infty} e^{-\delta t} \zeta_{t} h_{t}=0$

$\lim _{t \rightarrow \infty} e^{-\delta t} \mu_{t} K_{t}=0$

Linearising first order condition (10) around the steady state and using equation (12) and the assumptions (4), we have: $\left(l_{t}-\bar{l}\right)=0$.

By equation (13), as predicted by the standard consumption habits model, a gradual adjustment in consumption implies that leisure and thus labour supply act as a jumpdiscontinuous variable that fully adjusts to the exogenous shocks at the impact. This is the effect that gives the same results as in Graham (2003). Following negative real after-tax income shock, according to Graham (2003), we can anticipate an increase in labour supply that fully offsets the impact of the changes in income. In the absence of financial assets, households will fully adjust their leisure to smooth consumption. Thus future changes in consumption should be financed by changes in the asset positions of the households. 
As shown in Appendix 1 below, first order conditions (8)-(12) imply that

$$
\left[\begin{array}{l}
\dot{h} \\
\dot{\xi}
\end{array}\right]=A\left[\begin{array}{l}
h_{t}-\bar{h} \\
\xi_{t}-\bar{\xi}
\end{array}\right]
$$

where

$$
\begin{array}{ll}
a_{11}=-\lambda \frac{U_{C C}+U_{C h}}{U_{C C}}<0 & a_{12}=-\frac{\lambda^{2}}{U_{C C}}>0 \\
a_{21}=\frac{U_{h C}^{2}-U_{h h} U_{C C}}{U_{C C}}>0 & a_{22}=r-a_{11}>0
\end{array}
$$

Hence, saddle-path stability, which requires that $\operatorname{det} A<0$, is assured.

To derive solutions to the system given in equation (14), let $\phi<0$ be a negative eigenvalue of $A$, so that:

$\phi=\frac{1}{2}\left[r-\sqrt{r^{2}-4 \operatorname{det} A}\right]$

By definitions (14) and (15), and assumptions (4) we can conclude that $\phi<0$ exists.

Furthermore, by the assumptions (4) and as shown in the Appendix 1:

$$
-\phi<,>\lambda \Leftrightarrow \lambda>,<-r\left[\frac{U_{h h}+2 U_{C h}}{U_{C h}}\right]
$$

We express condition (17) in terms of the absolute magnitude of the negative eigenvalue, $\phi$, relative to the positive value of the speed of habits stock adjustment to the steady state. Such exposition is consistent with Mansoorian (1993). Note that here we allow for $U_{c h}>-0.5 U_{h h}>0$ as one of the possible outcomes in condition (17). This possibility is of impart here only in so far that in Model 2 we will impose a corresponding restriction on the allowable size of $U_{c h}$ relative to $U_{h h}$. However, in Model 1 there are no intuitive reasons for such restriction. More on this issue follows in part 2 below.

Technically, inequalities in condition (17) imply that there exist two different regimes with respect to the variables of choice response to changes in the rates of taxation. Whenever the marginal disutility of habits is strongly responsive to changes in the habitual stock relative to the speed at which the habits stock adjusts towards the steady state level, the negative eigenvalue of the process in system (14) dominates the speed of 
growth in the habits stock. The converse applies when the marginal disutility of habits is weakly responsive to changes in habits stock along the steady state path.

Note that by equations (15) and (16), since there are no cross effects of habits on leisure, $\phi<0$ can be interpreted as a rate of growth in the marginal utility of income due to the speed of adjustment in habits. When $U_{C h}$ is relatively high, so that habits have a strong effect on the marginal utility of consumption, the marginal utility of income is strongly influenced by habits as well. In this case, $-\phi<\lambda$, so that the speed at which consumption catches up with habits is above the speed at which marginal utility of income falls with the increase in the habits stock.

Standard form solutions for the system of two equations, (14), are given by the stable arm equations:

$$
\begin{aligned}
& \left(h_{t}-\bar{h}\right)=\left(h_{0}-\bar{h}\right) e^{\phi t} \\
& \left(\xi_{t}-\bar{\xi}\right)=-\left(h_{0}-\bar{h}\right) e^{\phi t} \frac{\left(\phi U_{C C}+\lambda\left(U_{C C}+U_{C h}\right)\right)}{\lambda^{2}}
\end{aligned}
$$

Using equations (18) and (19), we can solve for the asset holdings of households. Linearise equation (3) around the steady state, using equation (13):

$$
\begin{aligned}
& \dot{B}_{t}=r\left(B_{t}-\bar{B}\right)+\Omega\left(h_{0}-\bar{h}\right) e^{\phi t} \\
& \Omega=-\frac{\phi+\lambda}{\lambda}>,<0 \Leftrightarrow-\phi>,<\lambda
\end{aligned}
$$

In the above, inequality on $\Omega$ arises from the assumptions (4) and by the inequalities (17).

Equation (20) provides a solution for the steady state deviation in asset holdings by households and the steady state differences in the habits stock:

$$
\bar{B}-B_{0}=\underbrace{\frac{\Omega}{\phi-r}}_{(-) /(+)}\left(\bar{h}-h_{0}\right)<,>0 \Leftrightarrow-\phi>,<\lambda
$$

Note that by equations (20) and (21), households' asset positions depend on the level of income taxation. This provides the analysis shown below. In addition, part 3 of this paper, and the Appendix 3 below, discuss the effects of the models parameters in the context of consumption, leisure and foreign asset holdings adjustments. 
In so far as our benchmark model predicts, we retain herein the main features of traditional habit formation in consumption models. When consumption in the recent past becomes more important in reference to future consumption, $\lambda$ rises and the optimal consumption for the future periods decreases. At the same time, as the importance of habits in the utility function increases (so that $U_{C h}$ is positive as assumed in (4) above), the optimal consumption increases as well in order to maintain a habitual standard of living.

Also, by inequalities (21), the household bond holdings do respond to changes in wages and consumption habits parameters. Outside the steady state, an increase in the habits endowment or a decrease in the habits stock steady state value (so that $\left(h_{0}-\bar{h}\right) \uparrow$ ) will lead to a faster growth rate in assets, as $\dot{B}_{t}$ falls. This occurs whenever the speed of habits convergence is low compared to the effect of habits on the marginal disutility of habits relative to their effect on the marginal utility of consumption. Hence, agents with a greater initial habits stock in consumption will tend to have slower growing asset positions, and subsequently a higher volume of bond holdings whenever the adjustment of habits stock to the steady state is slower. Since the steady state level of habits converges to that of consumption by equation (6), we have the link between the initial level of consumption and the asset accumulation behaviour of the households.

This link arises due to the negative effect of the habits stock on the intertemporal utility of consumption. Agents care about their income in two ways. First, income yields utility via consumption, second via demand for leisure. The second component is linked to the source of income. Income arising from savings (bonds) is not 'taxed' in terms of habits disutility and neither in this model is the labour income subject to habitual inertia. Hence, agents with stronger habits in consumption will fully substitute away from leisure in favour of savings (substitution effect). Secondly, ceteris paribus, agents with higher initial stock of habits will tend to allow lower variation in bond holdings away from the steady state (depth effect).

The impact of the speed at which the habits stock catches up with consumption $(\lambda)$ and the strength of habit formation effect preferences $\left(U_{C h}\right)$ on asset holdings by households and leisure will be further discussed in the following sub-section and in Part 3 below. 


\subsection{Effects of Tax Changes: General Solutions.}

To consider the effects of changes in income and consumption taxes, we differentiate equations (21), (6), (3), (1), (8), (9) and (10) around the steady state which, with minor manipulations, yield:

$$
\begin{aligned}
& d \bar{B}=\frac{\Omega}{\phi-r} d \bar{h} \\
& d \bar{B}=\frac{1}{r}[w d \bar{l}+d \bar{h}] \\
& d \bar{h}=\frac{r+\lambda}{U_{h h}+U_{h c}} d \bar{\xi} \\
& d \bar{l}=-\frac{\bar{\mu} w}{U_{l l}} d \bar{\tau}_{l} \\
& d \bar{h}=\frac{\left[d \tau_{c} \bar{\mu}-\lambda d \bar{\xi}\right]}{U_{c c}+U_{h c}}
\end{aligned}
$$

Observe that in equation (22): $\frac{\Omega}{\phi-r}>,<0 \Leftrightarrow-\phi<,>\lambda \Leftrightarrow \Omega<,>0$

This system of equations can be solved for the effects of changes in the steady state level of habits stock in consumption, as shown in Appendix 1, to yield:

$$
\frac{d \bar{h}}{d \tau_{c}}=\frac{\bar{\mu} d \tau_{c}}{U_{C C}+\frac{2 \lambda+r}{\lambda} U_{C h}+U_{h h}}
$$

Finally from the first order condition (10) we have:

$$
\bar{\mu}=\frac{U_{l}}{w\left(1-\tau_{l}\right)}
$$

Equations (22)-(28) allow us to solve for the effects of changing the rate of taxation on the variables of choice.

\subsection{Effects of Consumption Tax Change.}

Starting as standard from the initial setting where both tax rates are originally at zero, suppose a government imposes a permanent change in consumption tax, so that 
$d \tau_{C}>0=d \tau_{l}$. Using equations (22)-(28) we can now solve for the resulting effects of consumption tax increase on the variables of choice. As shown in the Appendix 1:

$$
\begin{aligned}
& \frac{d \bar{h}}{d \tau_{C}}=\frac{d \bar{C}}{d \tau_{C}}=\frac{U_{l}}{w\left(1-\tau_{L}\right)\left[U_{C C}+\frac{2 \lambda+r}{\lambda} U_{C h}+U_{h h}\right]}<0 \\
& \frac{d \bar{l}}{d \tau_{C}}=-\frac{\phi(r+\lambda)}{(\phi-r) \lambda} \frac{d \bar{h}}{d \tau_{C}}>0 \\
& \frac{d \bar{B}}{d \tau_{C}}=\frac{\Omega}{\phi-r} \frac{d \bar{h}}{d \tau_{C}}>,<0 \Leftrightarrow-\phi>,<\lambda
\end{aligned}
$$

In the case of habitual consumption alone, by using equation (31), we can distinguish two possible environments.

- In the first case, whenever habits move to the steady state level at a sufficiently high speed, an increase in consumption tax implies disposing of the household financial wealth along the transition path.

- However, when habits are slow to adjust, households accumulate financial wealth along the transition path.

Intuitively, the costs of higher taxation net of leisure adjustments can be borne by either lower consumption today or lower consumption in the future. Since consumption is sluggish due to habits, while leisure adjusts instantaneously, the adjustments in consumption needed to compensate the household for higher taxation burden will be borne by the financial assets. When habits are fast to adjust to the new steady state, as is standard in consumption habits literature, consumption adjustments are insufficiently strong in the short run as consumers are less willing to postpone current consumption in favour of future consumption. As a result over time, consumers continue to lower their consumption and thus generate the need for extra smoothing through lowering of their asset holdings along the way. The converse applies to the case of slowly adjusting habits.

We thus distinguish two cases:

Case A: $-\phi>\lambda$

Case B: $-\phi<\lambda$ 
Figure 1 below illustrates the adjustment processes for leisure, consumption and asset holdings of the households facing an increase in consumption tax in Case A. The details of solutions for dynamics are given in the Appendix 1.

\section{Figure 1. ABOUT HERE.}

Leisure and labour supply act as jump-discontinuous variables in response to changes in income tax. Under the assumptions above, an increase in consumption tax rate will have an effect of raising leisure at the impact level to the higher steady state level. The resulting decrease in labour supply by the households allows for downward overshooting at the impact in consumption. As labour income of the households falls due to the dual effects of real after-tax wage decline and the contraction in labour supply, household asset holdings remain intact at impact. Consumption of the households initially falls below the new lower steady state level and then proceeds to gradually adjust upward toward the steady state. Savings from overshooting the new steady state level of consumption complement asset holdings of the households. Hence, a lower consumption demand fully absorbs the shock to income resulting from a higher consumption tax. As consumption approaches the new steady state gradually while labour supply instantaneously falls to the new steady state level, the surplus savings generated by the wedge between the post-impact consumption levels and the new steady state are absorbed by the households into higher holdings of assets. The economy continues to accumulate assets as it moves towards the new steady state.

Figure 2 below illustrates the case B. When habits adjust to a new steady state level at a relatively high speed, the negative impact of the more distant consumption decisions on the marginal utility of consumption is diminished. Agents, therefore, are less willing to adjust their consumption at impact. The reason for this is that at impact, the households are more inclined to maintain their habitual standard of living determined before the changes in consumption tax rate. This implies that households are willing to draw down their savings in order to finance an incomplete adjustment of consumption toward the lower steady state. A partial reduction of consumption at impact finances, in part, the immediate upward jump adjustment in leisure. Over time, consumption continues to decline toward the new steady state. The reduction in the asset position of households augments this decline to fully finance a greater demand for leisure in the new steady state. 


\section{Figure 2. ABOUT HERE.}

With the exception of explicitly incorporating labour supply decisions into the household optimisation problem, the results presented above are consistent with the general literature on habit formation in consumption (see, for example Mansoorian, (1993)). In simple terms, as with any exogenous shock to real income, an increase in the consumption tax acts to amplify the importance of habits in consumption in the overall decision of the agents. This results in a slower adjustment in consumption to the new steady state. The substitution effect in leisure continues to operate in the model, but is now magnified by the habits effects of rising consumption along the adjustment path to a new lower steady state. Hence, changes in labour supply and leisure are more pronounced in the model with habits in consumption than in the model where consumption is allowed to adjust instantaneously. This is counterintuitive, given that in general labour supply adjustments are slower in response to changes in income than the adjustments in consumption. Gurdgiev (2003) presents a summary of some evidence in favour of an argument that leisure adjusts slower than consumption. In this case, in the context of our model, the asset holdings of households act as the main shock absorber.

As shown in Appendix 1, the effects of an income tax change on the variables of choice in this model are identical in direction to the effects of consumption tax changes discussed above. This result confirms theoretical predictions of the RBC models that show the equivalence of consumption and labour income taxes in the standard models with no habit formation (e.g. see Judd (1985), Chamley (1986), and Milesi-Ferretti and Roubini (1998)). In general, consumption tax introduces a singularly important effect in household decision-making: the trade-off between labour supply and leisure is tilted by a rise in the consumption tax rate in the direction of the greater demand for leisure. Outside the production decisions involving productive capital accumulation by the agents, income tax has the same effect.

Yet, the endogenous growth literature (see Jones, Manuelli and Rossi (1993) for an excellent discussion) disputes this qualitative equivalence principle. So do the majority of the empirical studies regarding asset positions and investment decisions of households. These show that investment (in our model - asset positions) is commonly found to be negatively correlated with labour income tax and positively correlated with consumption 
tax. For example, Mendoza, Milesi-Freretti and Asea (1997) show the regularity for a panel of nineteen OECD economies.

Hence, due to the counterintuitive results of the benchmark model mentioned above, it is warranted to explore other possible applications of the habit formation mechanism. The objective of such an exploration is to account for both persistence of consumption and even stronger persistence of labour supply in the household responses to the exogenous income shocks given by the changes in tax rates.

\section{Part 2. A Model of Weakly Inseparable Consumption and Leisure in Comprehensive Habits.}

To address the criticism supplied in the conclusions drawn from the solutions to Model 1 above, we examine a model of preferences that are history-dependent in all components of choice. The reason for this is that we want a model that can account for the sluggish dynamic adjustments in both consumption and leisure.

By analogy with Model 1 above, restricting leisure to be a habitual good, while allowing consumption to change without any reference to past choices in Model 2 will simply yield a model in which consumption is jump-discontinuous. In this regard, whenever habits stock arises from a single choice variable (either consumption or leisure, but not both simultaneously), the habitual variable will exhibit gradual adjustment. The variable that is independent of habits will act as a jump-discontinuous shock-absorbing variable with complete adjustment to the new steady state at impact. This can be seen from the first order conditions (10) and (11) in the case when habits are formed in consumption alone.

Clearly, in order to achieve the desired dual persistence in both choice variables (consumption and leisure), it is important to introduce history-dependence in both of these variables simultaneously. With this in mind, we shall extend the earlier model of preferences to include the adjacent complementarity in both consumption and leisure. This link between consumption and leisure in habits stock determination generates the main differences between Models 1 and 2. 


\subsection{General Solution.}

For simplicity, we assume that both consumption and leisure contribute to the stock of comprehensive habits. We assume that the law of motion for comprehensive habits stock follows the same process as in the earlier model, so that

$\dot{h}_{t}=\lambda_{c}\left[\eta C_{t}+(1-\eta) w l_{t}-h_{t}\right]$

By equation (32), the habits stock is a weighted average of the complete history of choice variables. Note that the model predictions do not change qualitatively if we replace the real expenditure on leisure with the level of leisure in equation (32). At the same time, given our assumption that the price of consumption goods is set at 1 we can interpret the stock of habits described by the law of motion (32) as being referenced to both types of expenditure instead of the levels of consumption and leisure. Thus overall, relative scaling of variables employed in equation (32) is of little analytical importance in the model. We can, therefore, interpret equation (32) as a law of motion for habitual stock determined by the total expenditure by the households. In this context, $h_{t}$ is the household income, net of foreign asset holdings.

Treating habits as a function of real expenditure, rather than as measured in the levels of consumption and leisure allows us to resolve the issue of different scaling of the two components of the utility function. Since we restrict time endowment at unity, while the price of consumption is assumed to be 1, specifying habits in terms of real expenditure on both consumption and leisure, measured in terms of consumption goods, allows us to capture the possibility of a partial complementarity of leisure and consumption. When households trade away from consumption in favour of leisure they may choose to do so either by demanding more leisure hours or by switching away from pure consumption goods in favour of the leisure-complimentary goods. In the latter case, total leisure expenditure of the household will rise even when the leisure hours demanded may stay fixed. The complementarity of consumption and leisure can, in our model, be captured without explicit separation of consumption goods and leisure-complementing goods by considering the habits in the real expenditure on consumption and leisure, rather than in the levels of consumption and leisure. We will further elaborate on this in parts $2.3,2.4$ and part 3 below. 
At the same time, this presents an interesting case for future analysis vis-à-vis the effects of the after-tax price and wage changes on leisure and consumption. For example, suppose that consumption and leisure expenditures form a signal of status of the agent. Then both the habitual standard of living and status standing of individuals will be altered in response to changes in prices and wages. As a result of this, in the models with explicit analysis of changing prices, a higher price of consumption implies that, the households are interested in smoothing both the habit-forming consumption and leisure. Thus a lower weight will be placed by the households on keeping the leisure component of habit stock smoothed. This in turn means that agents will be more willing to adjust their leisure spending in response to the exogenous income shocks.

On the other hand, higher wage rates will be associated with a greater weight of leisure in determination of the comprehensive habits stock, so that leisure adjustments will be more sluggish. Some evidence shows that in the environment of high price inflation, agents are willing to incur greater cost in obtaining consumption to maintain their standard of living, at the expense of supplying more labour. Thus, for example, in 1920's Germany, women commonly abandoned both their labour and leisure activities in order to convert their husbands' earnings into consumption goods. The resulting losses of wages, or household production, were compensated for by the lower losses of real wages to a rampant inflation.

These effects will remain unexplored in the present paper, offering an interesting avenue for future inquiry. However, the link between the leisure expenditure and the consumption expenditure in our model can be partially investigated by the consideration of the effect of parameter $\eta$. As mentioned above, $\eta$ on consumption, leisure and foreign assets position, as discussed in Part 3 below and in the Appendices 3 and 4.

In general, the adjacent complementarity of leisure and consumption in the law of motion for habits, as well as the comprehensive habits specification, are similar to the Ryder and Heal (1973). In the Ryder and Heal (1973) model, the habitual standard of living is a weighted average of past choices of money balances and consumption, while the utility function is weakly inseparable across real balances and consumption. In our model, the spirit of their specification is preserved with respect to leisure and consumption acting as joint determinants of the habitual reference stock. 
To specify preferences allowing for the combined effects of consumption and leisure on habits stock, assume that as in Model 1, the utility function is separable across consumption and leisure:

$U\left(C_{t}, l_{t} ; h_{t}\right)=v^{1}\left(C_{t}, h_{t}\right)+v^{2}\left(l_{t}\right)+v^{3}\left(h_{t}\right)$

where $v^{3}\left(h_{t}\right)$ captures the direct effects of habits on the utility of leisure.

In the following section 3 of this paper we will explore the model under the added simplifying assumption that habits are completely separable from both consumption and leisure, i.e. $v^{1}\left(C_{t}\right)$. The corresponding Ryder-Heal assumptions in addition to those listed in (4) are:

$U_{l}>0$, and $U_{l l}<0$

$U_{l h}^{2}-U_{l l} U_{h h} \leq 0$

$U_{l}+U_{h}>0$

$U_{l h}=U_{C l}=0$

Finally the budget constraint (3) and the rebate identity (1) continue to hold as before.

Once again, our assumptions allow for a broad range of utility functions, including those covered in Faria (2001). The strong assumption that preferences are separable in terms of habit component in leisure, so that $U_{l h}=0$, is maintained here for the reasons of analytical simplicity. Since the cross effect of habits on leisure should be positive, as argued for the same effect in consumption, it would simply reinforce the effect of the consumption-habits link in the results below.

The current value Hamiltonian for the household optimisation problem is now given by:

$$
\begin{aligned}
H_{C V}= & U\left(C_{t}, l_{t} ; h_{t}\right)+\mu_{t}\left[r B_{t}+w\left(1-\tau_{l}\right)\left(1-l_{t}\right)-\left(1+\tau_{C}\right) C_{t}+T_{t}\right]+ \\
& +\xi_{t} \lambda_{c}\left(\eta C_{t}+(1-\eta) w l_{t}-h_{t}\right)
\end{aligned}
$$

The first order conditions for optimisation are:

$$
\begin{aligned}
& U_{C}=\left(1+\tau_{C}\right) \mu_{t}-\xi_{t} \lambda_{c} \eta \\
& -U_{h}+\xi_{t}\left(\lambda_{c}+\delta\right)=\dot{\xi}_{t} \\
& U_{l}=\mu_{t} w\left(1-\tau_{l}\right)-\xi_{t} \lambda_{c} w(1-\eta)
\end{aligned}
$$


$\dot{\mu}_{t}=\mu_{t}(\delta-r)$

As in Model 1, assumption (12) must be satisfied. In addition we impose the following transversality conditions:

$\lim _{t \rightarrow \infty} e^{-\delta t} \xi_{t} h_{t}=0$

$\lim _{t \rightarrow \infty} e^{-\delta t} \mu_{t} K_{t}=0$

where $K_{t}$ is defined in equation (5).

Solving the model as shown in the Appendix 2 we get:

$\left[\begin{array}{l}\dot{h} \\ \dot{\xi}\end{array}\right]=A_{c}\left[\begin{array}{l}h_{t}-\bar{h} \\ \xi_{t}-\bar{\xi}\end{array}\right]$

where

$$
\begin{array}{ll}
a_{11}=-\lambda_{c} \frac{\eta U_{C h}+U_{C C}}{U_{C C}}<0 & a_{12}=-\frac{\lambda_{c}^{2}}{U_{C C} U_{l l}}\left((1-\eta)^{2} w^{2} U_{C C}+\eta^{2} U_{l l}\right)>0 \\
a_{21}=\frac{U_{C h}^{2}-U_{C C} U_{h h}}{U_{C C}}>0 & a_{22}=r-a_{11}>0
\end{array}
$$

Note that by equations (40), the square of trace of $A_{c}$ is greater than $4 \operatorname{det} A_{c}$, satisfying saddle path stability conditions as stated in Chiang (1984). Furthermore, $\bmod \left(\operatorname{det} A_{c}\right)>1$ under assumptions (4) and (33) so that for $\phi_{c}$ being the negative eigenvalue of $A_{c}, \bmod \left(\phi_{c}\right) \neq 1$. This implies that the basin attraction for the saddle point is large, as stipulated in Kozlowski, et al (2001). Hence, with $\operatorname{det} A_{c}<0$, the saddle-point stability is automatically assured, while the solutions to the system are given as follows. Consider the system of two differential equations given by (39) and (40). The negative eigenvalue of this system is given by:

$\phi_{c}=\frac{1}{2}\left[r-\sqrt{r^{2}-4 \operatorname{det} A_{c}}\right]$

Then 


$$
\begin{aligned}
\lambda_{c}>,<-\phi_{c} & \Leftrightarrow \\
& \Leftrightarrow \lambda_{c}<,>\frac{r \eta U_{C h} U_{l l}}{w^{2}(1-\eta)^{2}\left(U_{C h}^{2}-U_{C C} U_{h h}\right)-\eta^{2} U_{l l} U_{h h}-2 \eta U_{C h} U_{l l}}
\end{aligned}
$$

Inequality (42) implies that preferences under conditions (33) exhibit the adjacent complementarity property defined by Ryder and Heal (1973) in terms of the composite choice of leisure and consumption expenditures.

Importantly, $\lambda_{c}$ as habits parameter has a direct effect on the overall speed of the choice variables adjustment to the steady state along the stable path. As discussed in greater detail in Part 3 of this paper, $\phi_{c}$ determines the speed with which habits stock adjusts to the steady state. At the same time, $\lambda_{c}$ captures the speed of growth in habits. As in the traditional habits in consumption models, higher $\lambda_{c}$ implies that recent past consumption and leisure expenditures play a greater role in determining the overall stock of habits. However, in addition to the traditional models of habit formation, the comprehensive habits model allows us to differentiate between the two components of habits directly. Thus, by (32), $\lambda_{c} \eta$ captures the importance of the recent consumption choices, while $\lambda_{c}(1-\eta)$ captures the importance of the recent leisure expenditure choices.

Linearising the budget constraint:

$$
\dot{B}_{t}=r\left(B_{t}-\bar{B}\right)+\Omega_{c}\left(h_{0}-\bar{h}\right) e^{\phi t}
$$

where:

$$
\Omega_{c}=\frac{\lambda_{c} U_{C h}\left[\eta^{2} U_{l l}+w^{2}(1-\eta)^{2} U_{c c}\right]-U_{c c}\left(\phi_{c}+\lambda_{c}\right)\left[\eta U_{l l}+w^{2}(1-\eta) U_{c c}\right]}{\lambda_{c}\left[\eta^{2} U_{l l}+w^{2}(1-\eta)^{2} U_{c c}\right] U_{c c}}
$$

As shown in the Appendix 2, 
Case $A:-\phi_{c}<\lambda_{c} \Rightarrow \Omega_{c}<0$

Case $B:-\phi_{c}>\lambda_{c}>\frac{\phi_{c} U_{c c}\left[\eta U_{l l}+(1-\eta) w^{2} U_{c c}\right]}{U_{c h}\left[\eta^{2} U_{l l}+(1-\eta)^{2} w^{2} U_{c c}\right]-U_{c c}\left[\eta U_{l l}+(1-\eta) w^{2} U_{c c}\right]} \Rightarrow$

$$
\Rightarrow \Omega_{c}<0
$$

Case $C: \lambda_{c}<\frac{\phi_{c} U_{c c}\left[\eta U_{l l}+(1-\eta) w^{2} U_{c c}\right]}{U_{c h}\left[\eta^{2} U_{l l}+(1-\eta)^{2} w^{2} U_{c c}\right]-U_{c c}\left[\eta U_{l l}+(1-\eta) w^{2} U_{c c}\right]}<-\phi_{c} \Rightarrow$

$$
\Rightarrow \Omega_{c}>0
$$

In (45), case $A$ is the case of high speed of habits stock growth, $\lambda_{c}$ relative to the speed of the choice variables convergence to the steady state, $-\phi_{c}$. In cases B and C condition (45) can be re-written as:

$1-\frac{\phi_{c}}{\lambda_{c}}>;<-\frac{U_{c h}\left[\eta^{2} U_{l l}+(1-\eta)^{2} w^{2} U_{c c}\right]}{U_{c c}\left[\eta U_{l l}+(1-\eta) w^{2} U_{c c}\right]}>0$

In the above, the numerator represents the weighted second order effects of habits on the marginal utility consumption, with the weights being the shares of consumption and leisure in the overall habits stock determination, respectively. The denominator represents the overall second order effects of consumption on the marginal utility of consumption, accounting for both:

- The direct effects of consumption on the marginal utility of consumption.

- The effect of consumption on the marginal disutility of habits.

Overall, relative speed of system convergence net of habits speed of convergence to the new steady state, i.e. the left-hand side of the above inequality, is increasing in the following components:

- the importance of habits in the marginal utility of consumption, i.e. the direct effect of habits, as measured by $U_{c h}$;

- the second order effect of leisure and consumption on the marginal disutility of the comprehensive habits stock, $\eta^{2} U_{l l}+(1-\eta)^{2} w^{2} U_{c c}$, i.e. indirect effect of habits; 
- the second order effect of consumption on the marginal utility of consumption, i.e. the direct effect of consumption;

- and finally, with the importance of the habits stock in the marginal disutility of habits, $\eta U_{l l}+(1-\eta) w^{2} U_{c c}$

Hence, in case $\mathrm{B}$, the speed of habits stock growth along the steady state path, $\lambda_{c}$ is large relative to the second order effect of the weighted habits-related expenditure.

Alternatively, case B can be interpreted as a case where habits are associated with relatively high speed of adjustment and relatively high effect on the marginal utility of consumption, so that both $\lambda_{c}$ and $U_{C h}$ are high. In case $\mathrm{C}$, the marginal utility of consumption is less impacted by the overall stock of habits, so that $U_{C h}$ is relatively low.

This is similar to the discussion following equation (17) in Model 1. However, in the context of our model with comprehensive habits, we no longer can assume, as was done in Model 1 under the condition (17), that $\eta U_{h h}+U_{c h}>0$. As was mentioned earlier, as well as discussed in the Appendix 2, we must restrict, hereinafter $\eta \bmod \left(U_{h h}\right) \geq U_{c h}$.

Setting $\eta=1$ gives leisure expenditure a zero weight in habits stock. In this case, we attain the same results as shown in Model 1. Alternatively, setting $\eta=0$ yields results for a model where leisure is the only habitual good. In the latter case, $\Omega_{c}>0$ unambiguously. As a result, by equation (35), consumption acts as a jump variable. Under the assumption of zero first order effects of habits on the marginal utility of leisure, only consumption and habits are linked through a second order effect. Thus asset holdings of the households will always countermove with leisure habits stock whenever no habitual consumption is built into the model. This is captured below by equation (46). The short run effects of tax policy changes will be absorbed by consumption, while the long run effects will be at least partially checked by changes in the household's financial assets.

\subsection{Effects of Tax Changes: General Solutions.}

As in the earlier model, the following equations determine the effects of income tax change on the variables of choice: 


$$
\begin{aligned}
& d \bar{B}=\underbrace{\frac{\Omega_{c}}{\phi_{c}-r}}_{\substack{(+) \text { if } A \text { or } B \\
(-) \text { if } C}} d \bar{h} \\
& d \bar{h}=\underbrace{\frac{M_{2}}{M_{1}} d \tau_{C}}_{(-)}+\underbrace{\frac{M_{3}}{M_{1}}}_{(+)} d \tau_{l}
\end{aligned}
$$

where

$$
\begin{aligned}
& M_{1}=-\frac{\left(\lambda_{c}+r\right) U_{C C}\left[(1-\eta)^{2} w^{2} \lambda_{c} U_{h h}+U_{l l}\right]+\lambda_{c} \eta U_{l l}\left[\eta U_{h h}+U_{c h}\right]}{(1-\eta)^{2} w^{2} \lambda_{c} U_{C h}-\eta\left(\lambda_{c}+r\right) U_{l l}}<0 \\
& M_{2}=\bar{\mu}=\frac{U_{C}}{1+\tau_{C}}-\frac{\lambda_{c} \eta U_{h}}{\left(\lambda_{c}+r\right)\left(1+\tau_{C}\right)}=\frac{U_{l}}{w\left(1-\tau_{l}\right)}+\frac{\lambda_{c}(1-\eta) U_{h}}{\left(\lambda_{c}+r\right)\left(1-\tau_{l}\right)}>0 \\
& M_{3}=M_{2}(1-\eta) w^{2}\left[\frac{\left(\lambda_{c}+r\right) U_{C C}+\eta \lambda_{c} U_{h c}}{w^{2}(1-\eta)^{2} \lambda_{c} U_{C h}-\left(\lambda_{c}+r\right) \eta U_{l l}}\right]<0
\end{aligned}
$$

Finally,

$$
\begin{aligned}
d \bar{l}= & \frac{\eta w\left(\lambda_{c}+r\right) \bar{\mu}}{(1-\eta)^{2} w^{2} \lambda_{c} U_{h c}-\left(\lambda_{c}+r\right) w U_{l l}} d \tau_{l}+ \\
& +\frac{\lambda_{c}(1-\eta) w\left[\eta U_{h h}+U_{c h}\right]}{(1-\eta)^{2} w^{2} \lambda_{c} U_{h c}-\left(\lambda_{c}+r\right) w U_{l l}} d \bar{h}
\end{aligned}
$$

Using equations (46)-(51), as shown in the Appendix 2, we can solve the model for the choice variables responses to the changes in labour income and consumption tax rates.

\subsection{Effects of Labour Income Tax Change.}

We now consider the effects of a permanent increase in the labour income tax. Assume $d \tau_{l}>0=d \tau_{C}$. As shown in the Appendix 2, the following equations determine the response of the choice variables.

$$
\begin{aligned}
& \frac{d \bar{h}}{d \tau_{l}}=\frac{M_{3}}{M_{1}}>0 \\
& \frac{d \bar{B}}{d \tau_{l}}=\frac{\Omega_{c}}{\phi_{c}-r} \frac{d \bar{h}}{d \tau_{l}}>;<0 \quad \Leftrightarrow \quad \text { cases } A, B ; \text { case } C
\end{aligned}
$$

While for leisure: 
$\frac{d \bar{l}}{d \tau_{l}}=\frac{w \lambda_{c}(1-\eta)\left[\eta U_{h h}+U_{C h}\right]}{(1-\eta)^{2} w^{2} \lambda_{c} U_{C h}-\left(\lambda_{c}+r\right) \eta U_{l l}} \frac{d \bar{h}}{d \tau_{l}}<0$

Specifically for the assumptions of the model, condition (54) requires that

$$
-\frac{U_{C h}}{U_{h h}}<\eta<1
$$

Condition (55) confirms the intuitive argument concerning the second order effects of habits on consumption alone made in the preceding subsection. This assumption is retained throughout the remainder of Part 2. The intuition behind it is that $\eta$ captures the importance of consumption in determining overall stock of habits. When $\eta$ is extremely low, as would be the case when condition (55) is violated, our model behaviour becomes dependent almost exclusively on the habituality of leisure expenditure alone. In this case, the households' motive for smoothing applies only to leisure demand. This in turn generates the situation where consumption absorbs all effects of tax policy shocks. In this case taxation is distortionary in so far as an increase in the labour tax rate will result in an unambiguous increase in leisure demand and a corresponding fall in consumption.

Finally for consumption:

$$
\frac{d \bar{C}}{d \tau_{l}}=\frac{1}{\eta} \frac{d \bar{h}}{d \tau_{l}}-\frac{(1-\eta)}{\eta} \frac{d \bar{l}}{d \tau_{l}}>0
$$

From (52)-(55):

$$
\begin{aligned}
& \text { if } \eta>1 / 2 \Rightarrow \frac{d \bar{C}}{d \tau_{l}}<w \bmod \frac{d \bar{l}}{d \tau_{l}} \\
& \text { if } \eta<1 / 2 \Rightarrow \frac{d \bar{C}}{d \tau_{l}}>w \bmod \frac{d \bar{l}}{d \tau_{l}}
\end{aligned}
$$

To interpret inequalities in (57), consider again the role of $\eta$. As $\eta$ rises, the weight of consumption component of the habits stock law of motion rises as well. This implies, ceteris paribus, that the households' propensity to adjust their consumption falls relative to their propensity to adjust their leisure demand. In other words, the higher is $\eta$, the greater is the role of leisure in absorbing tax policy changes relative to consumption.

Next we proceed to discuss the three possible cases A through C. 


\subsubsection{Case A: $-\phi_{c}<\lambda_{c}$}

The adjustment dynamics in case A are shown in Figure 3.

\section{Figure 3. ABOUT HERE}

In the case of high speed of adjustment in habits stock, as can be seen from Figure 3 and Appendix 2, at the moment of impact, stock of habits jumps up, but remains below the new steady state level. This implies that consumption adjusts incompletely to the new lower steady state. At the impact leisure falls, undershooting the new steady state. The reason for this is that at impact, an incomplete adjustment in consumption prevents partial adjustment of leisure in the absence of changes in asset holdings.

The reason for this is that in the environment of the high speed of habits adjustment to the steady state (case A), households attempt to maintain a habitual level of consumption and leisure simultaneously. Overall, in case $\mathrm{A}, U_{C h}$ is relatively small in comparison with $\eta U_{h h}$ (or $\lambda_{c}$ is relatively large) as required to make $\phi_{c}$ relatively small in absolute value. Thus the costs of habits in terms of substitution of present consumption for future consumption will be dominated by the benefits of adjusting leisure today relative to the future. Agents will substitute in favour of future consumption and present leisure in relative terms (so that consumption adjustment at impact is incomplete and less deep than a corresponding adjustment in leisure).

Over time, as consumption rises further toward the new steady state level, leisure rises as well and labour supply falls. However, on the net, habits are rising, since adjustments in consumption are complimented by the adjustment in leisure. Part of the original leisure fall at the impact will be absorbed into higher asset holdings. Agents therefore will substitute away from leisure and in favour of consumption, allowing for savings from increased labour supply to partially compensate for a smaller consumption increase.

Note that in contrast to case B in Model 1, in Model 2, case A, there is overshooting result with respect to leisure. In Model 1, leisure is a non-habitual good, so that an instantaneous adjustment of leisure absorbs the shock allowing for the impact change in consumption. Financial assets provide added smoothing to consumption. 
In Model 2, although leisure is smoothed alongside of consumption, habits move fast relative to the low weight of leisure in the overall habits stock. This implies that leisure will act as the main variable bearing the cost of adjustment at the impact. The result is logical, since if habits are fast moving, households will have lower incentives to delay adjustments to the new steady state. At the same time, since leisure is relatively less important as a determinant of overall habits stock at any point in time, households will be more inclined to vary leisure along the adjustment path, allowing for a smaller change in consumption. Hence, the difference across the models arises due to the stronger effect of habits speed of adjustment and due to the fact that this effect dominates the overall importance of leisure in the comprehensive habits stock. Unlike in Model 1 (case B), in case A of Model 2, overall, leisure demand falls in response to changes in the labour income tax rate. This is simply due to the fact that in Model 2 households are interested in smoothing both consumption and leisure expenditures. This prevents them from absorbing all the shocks into a single variable of choice along the adjustment path.

2.3.2. Case B: $0<\frac{\phi_{c} U_{c c}\left[\eta U_{l l}+(1-\eta) w^{2} U_{c c}\right]}{U_{c h}\left[w(1-\eta)^{2} U_{c c}-\eta^{2} U_{l l}\right]-U_{c c}\left[\eta U_{l l}+(1-\eta) w^{2} U_{c c}\right]}<\lambda_{c}<-\phi_{c}$.

Case B corresponds to the environment of moderately fast moving habits. As shown in Appendix 2, habits overshoot the new (higher) steady state level at the impact. Once again, fast adjustment of habits stock implies that costs of accumulating habitual standard of living accrue over a shorter period of time. However, at impact, consumption rises above the new steady state level whenever the share of consumption in overall habits law of motion is low enough $(\eta<1 / 2)$.

The overshooting in consumption, in the case of $\eta<1 / 2$, arises due to the fact that in case B, disutility of habits in second order effects dominates the effect of habits on the marginal utility of consumption. However, with low relative weight of consumption in the overall habits stock, leisure becomes the dominant smoothing variable. Thus, along the adjustment path, consumption component of the habits stock can be sacrificed by the household to a greater degree than the leisure component. Following impact, leisure falls below the new lower steady state and then proceeds to rise over the adjustment period. The converse applies in the case where $\eta>1 / 2$. 
Overtime, as the asset position improves, leisure rises (whenever $\eta<1 / 2$ ), financed by the falling consumption. These dynamics are shown in Figure 4 below.

\section{Figure 4. ABOUT HERE}

An interesting aspect of this scenario is that, in case A, taxes on labour income generate a counter-movement between labour supply and consumption along the adjustment path and co-movement at the impact. In case B this relationship is preserved. Thus case A confirms, while case B contradicts Barro and King (1984) model predictions. In this context, in the case B, due to habits in leisure and separability of leisure from habits stock in preferences, leisure acts as the main utility stabilising component whenever its share of habits stock law of motion is relatively high, $\eta<1 / 2$. This requires a strong reduction in consumption expenditure. In case A, with the speed of habits adjustment being relatively high, leisure is relatively less important as a utility stabilising component, so that both leisure and consumption are smoothed simultaneously, while leisure continues to dominate consumption as the main utility-stabilising component of the model.

2.3.3. Case C: $0<\lambda_{c}<\frac{\phi_{c} U_{c c}\left[\eta U_{l l}+(1-\eta) w^{2} U_{c c}\right]}{U_{c h}\left[w(1-\eta)^{2} U_{c c}-\eta^{2} U_{l l}\right]-U_{c c}\left[\eta U_{l l}+(1-\eta) w^{2} U_{c c}\right]}<-\phi_{c}$.

Finally in case $\mathrm{C}$, the habits stock slowly moves to the new lower steady state. As a result of this at impact, habits overshoot the new (higher) steady state level, as in case B above. Similarly, as in case B, leisure falls down part of the way towards the new lower steady state if its share of habits stock is relatively high $(\eta<1 / 2)$, or overshoots the lower steady state target if it share of habits stock is relatively low $(\eta>1 / 2)$. Once again, recall that these effects are driven by the relative importance of habits in terms of the marginal utility of consumption effect. Since, following the impact, habits are slow to move, while the marginal utility of consumption is relatively weakly responsive to habits change (as required by the inequality above), agents have a greater incentive to use leisure as a smoothing variable. As a result, consumption overshoots the long run target whenever $\eta<1 / 2$. The converse dynamics occur in case of $\eta>1 / 2$. As such, case $\mathrm{C}$ represents a reversal of the results presented in case B above. 
Over time, as asset positions are altered, consumption slowly falls toward a new steady state from its overshooting position, while leisure continues to fall as well. The assets are absorbed into the rising overall expenditure. Figure 5 below provides the dynamics for consumption, leisure and asset holdings of the households.

\section{Figure 5. ABOUT HERE}

\subsection{Effects of Consumption Tax Change.}

Finally we consider the effects of a one-time permanent increase in consumption tax, so that $d \tau_{C}>0=d \tau_{l}$. From equations (46)-(51) we can see that

$$
\begin{aligned}
& \frac{d \bar{h}}{d \tau_{C}}=\frac{M_{2}}{M_{1}}<0 \\
& \frac{d \bar{B}}{d \tau_{C}}=\frac{\Omega_{c}}{\phi_{c}-r} \frac{d \bar{h}}{d \tau_{c}}>;<0 \Leftrightarrow \text { case } C ; \text { cases } A, B \\
& \frac{d \bar{l}}{d \tau_{C}}=\frac{\lambda_{c}(1-\eta) w\left[\eta U_{h h}+U_{C h}\right]}{(1-\eta)^{2} w^{2} \lambda_{c} U_{C h}-\eta\left(\lambda_{c}+r\right) U_{l l}} \frac{d \bar{h}}{d \tau_{c}}>0 \Leftrightarrow \eta>-\frac{U_{C h}}{U_{h h}} \\
& \frac{d \bar{C}}{d \tau_{C}}=\frac{d \bar{h}}{d \tau_{c}} \frac{1}{\eta}-\frac{(1-\eta)}{\eta} \frac{d \bar{l}}{d \tau_{c}}<0
\end{aligned}
$$

and

$\bmod \left(\frac{d \bar{C}}{d \tau_{c}}\right)>w \frac{d \bar{l}}{d \tau_{c}}$

Note that in contrast with labour income tax case, in the case of consumption tax, adjustment in consumption is always deeper than adjustment in the leisure expenditure. This is so since changes in consumption tax have only price effects, while changes in the labour income tax have both price and income effects. A rise in consumption tax increases the price of consumption goods, leaving the price of leisure and income unchanged. Subsequently, households that are trading consumption in exchange for leisure respond to the substitution effect of price changes. In the case of labour income tax increase, the price of leisure rises, while labour income falls. Consequently, households face both the substitution effect of price change, and the reinforcing income effect. These effects relate 
to each other through the relative importance of leisure expenditure in the habits law of motion, $(1-\eta)$.

\subsubsection{Case A: $-\phi_{c}<\lambda_{c}$}

At the moment of the consumption tax policy change, the habits stock adjusts incompletely to a new higher steady state. At the same time, consumption falls part of the way toward the new steady state, while leisure rises towards the higher long-run level. Since the relative price of consumption rises, the opportunity cost of leisure falls making leisure more attractive. At the same time, habits adjust rapidly to the new steady state so that households place greater emphasis on maintaining their habitual standard of living and are unwilling to change either consumption or leisure dramatically. There are no overshooting results, as predicted by the traditional habit formation literature (see discussion of Model 1, case B).

Since consumption dominates the smoothing motive for the households (consumption weight in habits stock formation is high relative to the effect of habits on marginal utility

of consumption, which is necessary in order to make $\left.\eta>-\frac{U_{C h}}{U_{h h}}\right)$, leisure adjusts more in terms of overall expenditure than consumption following the impact. Overtime, this requires a reduction in the net savings. Asset holdings fall to the new steady state level. The adjustment dynamics in case A are shown in Figure 6.

\section{Figure 6. ABOUT HERE}

Relative to the comparable case $\mathrm{A}$ in the exercise involving changes in the labour income tax, the model predicts the reversal of the policy effects vis-à-vis direction of changes in asset holdings, consumption and leisure. Unlike in part 2.3.1 above, households respond to a rise in consumption tax by reducing financial wealth along the adjustment path that involves reduction in habits stock as well. This implies that households will tend to exhibit deeper adjustments in leisure relative to a decrease in consumption in the case of consumption tax along the long run adjustment path, than in the case of labour income tax. Most of the changes in consumption, on the other hand, occur at the impact as the 
households' efforts to maintain a given standard of living prevent them from changing consumption too aggressively in the future.

2.4.2. Case B: $0<\frac{\phi_{c} U_{c c}\left[\eta U_{l l}+(1-\eta) w^{2} U_{c c}\right]}{U_{c h}\left[w(1-\eta)^{2} U_{c c}-\eta^{2} U_{l l}\right]-U_{c c}\left[\eta U_{l l}+(1-\eta) w^{2} U_{c c}\right]}<\lambda_{c}<-\phi_{c}$.

Case B corresponds to the case of moderately fast moving habits. As in case A above, at impact, household habits overshoot downward the new (lower) steady state. However in contrast with the case A, consumption falls below the new steady state whenever leisure is the dominant habits component, i.e. $\eta<1 / 2$. The impact adjustment in consumption is incomplete whenever $\eta>1 / 2$, since a moderately high speed of adjustment in habits stock implies a strong smoothing incentive for household optimisation. At the same time, relative importance of consumption in the determination of the overall stock of comprehensive habits strengthens the propensity of households to use consumption as the main smoothing instrument. Thus, with $\eta<1 / 2$ consumption will move to absorb most of the adjustment, while with $\eta>1 / 2$ consumption will play such a role.

Case B, therefore, is associated with the change in the main variable of smoothing from leisure to consumption whenever the share of leisure expenditure in habits law of motion is high $(\eta<1 / 2)$. The opposite holds when the share of consumption in habits is high $(\eta>1 / 2)$. This fully contrasts the case of an increase in labour income tax, where leisure falls at the impact relative to the initial steady state level.

Over time, consumption and labour supply rise to the new steady state levels whenever leisure dominates habits, $\eta<1 / 2$. However, the stock of habits rises along the adjustment path to compensate for the downward overshooting at the impact. In this case in order to maintain a habitual standard of living, households increase consumption and leisure over time, which requires drawing down their financial assets. Figure 7 below provides the details.

\section{Figure 7. ABOUT HERE}

As can be seen from Figures 4 and 7, as well as Figures 3 and 6, consumption tax and labour income tax differ, in cases A and B, in their effects on consumption and asset 
position of the households. Strong preferences for consumption smoothing induced by fast moving habits and a relatively strong importance of habits in consumption vis-à-vis leisure implies that agents smooth consumption more in response to consumption tax change. This effect is amplified by the assumption on the separability of leisure and comprehensive habits stock in the instantaneous utility function. The latter reason implies that in case B leisure can act as a stronger shock absorber than consumption. Hence, the households decrease their labour supply in response to a change in the relative price of consumption, while they will increase their labour supply in response to the change in the real after-tax wage.

2.4.3. Case C: $0<\lambda_{c}<\frac{\phi_{c} U_{c c}\left[\eta U_{l l}+(1-\eta) w^{2} U_{c c}\right]}{U_{c h}\left[w(1-\eta)^{2} U_{c c}-\eta^{2} U_{l l}\right]-U_{c c}\left[\eta U_{l l}+(1-\eta) w^{2} U_{c c}\right]}<-\phi_{c}$.

Case $\mathrm{C}$ corresponds to the environment of slow moving habits. This implies that habits stock falls at the impact below the new steady state level and then proceeds to rise over time. Slow moving habits and corresponding relatively low value of $\eta$ imply, in the case $\mathrm{C}$ that consumption becomes the predominant channel for intertemporal smoothing allowing leisure to strongly respond to the shocks whenever consumption dominates the habits, $\eta>1 / 2$. As a result of this, consumption falls below the new steady state at the impact, while leisure overshoots the new higher steady state. The initial jump in consumption is relatively strong vis-à-vis the complete adjustment to the new steady state, since habits tend to adjust strongly at the impact. This implies that habits will rise over time, driven by the consumption increases. At the same time leisure falls toward the steady state, which implies that over time households, will adjust their labour supply upward. The dual effect of rising consumption and falling leisure is absorbed into rising financial wealth of the households.

\section{Figure 8. ABOUT HERE}

Figure 8 above illustrates the dynamics of these adjustments. In contrast to the response to a rise in income tax, consumption tax yields the opposite direction effects for all variables involved with exception of habits. The reason for this is once again the reversal of the smoothing instrument from consumption (in part 2.3.3 above) in favour of leisure. 
Overall, case $\mathrm{C}$ is comparable to case $\mathrm{A}$ in Model 1 whenever consumption dominates habits law of motion, i.e. $\eta>1 / 2$.

\section{Part 3. Comparative Analysis of the Effects of Habits Parameters on Models 1 and 2.}

In general, habits in consumption literature recognises the fact that most of the habits in consumption models are sensitive to both the choice of the utility function assumptions and the choice of the parameter values. In this part of the paper we want to address these issues. Subsequently we will make two distinctions. In the first part, paragraph 3.1 will consider an assumed form of preferences that is closely coincident with the Ryder and Heal (1973) assumptions listed in conditions (4) and (33) above. As shown in the Appendix 3, these assumptions impose a set of constraints on the choice of the utility function that prevent us from determining the direct effects of the habits parameters in the context of Model 2.

Comparing the results of the two specification assumptions highlights the general difficulty of parameterisation of the habit formation models. Under complete separability of habits assumption employed below, the results, which are discussed in parts 1 and 2 of this paper are shown to be significantly altered. Once again, these differences arise from the violation of some of the assumptions (4) and (33) made below.

In the following, we assume that the utility function is logarithmic in both consumption and leisure net of a proportional share of the habits stock., so that $U\left(C_{t}, l_{t} ; h_{t}\right)$

corresponds to the case where

$U\left(C_{t}, l_{t} ; h_{t}\right)=\log C_{t}+k \log \left(l_{t}\right)-\gamma h_{t}$

Specification (64) allows for habits to be completely separable in utility from the variables of choice, so that neither marginal utility of consumption, nor marginal utility of leisure are directly effected by the habits. This assumption does not violate the assumptions made in (4). As shown in the Appendix 3 below, this assumption supports the existence of a steady state solution and the method of solution presented in Parts 1 and 2. However, an important limitation arises under equation (64): in the absence of cross effects of the 
habits on marginal utilities, as well as in absence of the second order effects of habits, habits stock behaves as a jump-discontinuous variable along the adjustment path. At the same time the asset holdings of households continue to act as the shock absorber at the impact, adjusting to the new steady state to compensate fully for the changes in habits stock.

These results arise due to the nearly exogenous nature of habits under the specification (64). If habits are completely separable in the within-period utility function, the households no longer smooth the actual habits stock, as habits do not have any second order effects. At the same time, in the first order effect, habits induce smoothing behaviour in terms of their components. This distinction is important and completely new to the model of comprehensive habits. If habits are determined solely by consumption alone, smoothing of consumption implies smoothing of habits, as the stock of habits evolves in a 1:1 relationship with the consumption. However, in case of comprehensive habits, households can keep habits stock fixed along the adjustment path by proportionately varying consumption and leisure expenditure. As long as two components of habits stock countermove, the stock of habits will not change.

At the impact, as shown below and in Appendix 3, households will be free to fully adjust their habits to the steady state. The cost of doing so in terms of the disutility generated by raising habits stock at the impact do not subtract from the marginal utility benefits of smoothing adjustments in leisure and consumption (since there are no cross effects). In addition, the costs of adjusting habits are not effecting directly the marginal disutility of habits. Again, as in the case of the model specification presented in the paragraph 3.1 above, the details of solutions are shown in the Appendix 3. Figure 9 below illustrates the dynamics of model adjustments.

\section{Figure 9. ABOUT HERE}

As can be seen from Figure 9, habits jump at the point of impact to a higher steady state level. With incomplete adjustment to the new steady state in leisure expenditure and consumption, a discrete jump in habits implies that leisure demand adjusts more in terms of the underlying expenditure than by consumption. Labour income therefore falls at the impact more than consumption expenditure. This implies that household asset position adjusts fully to the new lower steady state at the impact. 
This result is of dual importance in the context of this model. First, theoretically it shows that in presence of comprehensive habits, households are not only free to smooth both consumption and leisure. In the traditional models of habit formation the households must smooth habits stock along the lines of smoothing their consumption. Instead, in our model under the added assumptions of the present part, the comprehensive habits stock can be used by the agents to absorb all exogenous shocks. Thus our model separates smoothing variables from the necessity to smooth habits.

Second, our model of comprehensive habits, by separating smoothing instruments away from the habits stock, can be used to model the empirically documented possibility that households may be smoothing actual consumption while allowing the overall expenditure fluctuate freely. Becker (1965) argued that individuals may substitute away from expenditure in favour of allocating more time to household production, as the relative price of time falls. This possibility, as was argued in Part 2 above, is clearly evident in our model. However, under the added assumption of separable habits, the possibility that habits stock may exhibit complete adjustment at the impact, while the components of the habits stock may exhibit persistent deviations from the steady state, in our model is consistent with the Aguiar and Hurst (2004) empirical findings.

Aguiar and Hurst (2004) found that faced with anticipated changes in income, such as retirement, individuals exhibit evidence that marginal utility of consumption may be smoothed over time. These findings are related to the well-established literature on the socalled 'the retirement consumption puzzle'. The puzzle is usually defined as follows: For most agents, retirement represents an anticipated event, so that under the permanent income hypothesis, forward-looking agents will smooth their marginal utility of consumption. However, empirically, we know that upon the retirement, household consumption declines sharply.

In the context of our model, the puzzle can be theoretically explained as follows. As the cost of time spent in household production, rather than in costly leisure falls (as in the case of a rise in the labour income tax), households will smoothly move out of consumption and into household production, so that their consumption expenditure falls, while their consumption remains relatively stable (undershoots the long run target). At the same time, facing time-endowment constraint, the households will also move out of labour into leisure. As the result, households will smooth their consumption and leisure, while 
discretely adjusting their habits stock at the impact. The comprehensive habits stock is defined over the total household expenditure. At the same time, actual consumption and leisure are smoothed. Thus in our model, households may vary expenditure dramatically, while smoothing both consumption and leisure.

This point reinforces the nature of the model 2 first order conditions. Recall that by equations (35), (37) and (38) our households keep constant their marginal utility of income, while smoothing their consumption and leisure. In addition smoothing of consumption is not in one-to-one relation to the smoothing of leisure. Thus, in our model, the standard result of the intertemporal models of consumption no longer holds. Specifically, we no longer observe that there is a one-to-one mapping from the entire vector of expenditures to the marginal utility of wealth. Aguiar and Hurst (2004) argue that data supports our type of the argument over the traditional models of consumption.

To analyse the role played by the habit formation parameters in the model, consider the following implicit solution for the steady state level of consumption:

$$
\frac{1}{\bar{C}}=\frac{1+\tau_{c}}{\left(1-\tau_{l}\right)(w-\bar{C}+r \bar{B})}+\gamma \lambda_{c} \frac{\left[\eta\left(1-\tau_{l}\right)-(1-\eta)\left(1+\tau_{c}\right)\right]}{\left(\lambda_{c}+r\right)\left(1-\tau_{l}\right)}
$$

Table 1 below summarises the results derived in the Appendix 3.

As shown in Table 1, responses of both consumption and leisure to changes in the habits parameters are driven by the relative weight of each component in the overall comprehensive habits stock, $\eta$. For the case when consumption dominates the habits law of motion, $\eta>1 / 2$, habits stock falls with the strength of habits parameters $\gamma$ and $\lambda$ whenever consumption is relatively moderately weighted in the law of motion $\left(\eta<1 / 2<\frac{1+\tau_{c}}{2-\tau_{l}+\tau_{c}}\right)$. In the case when consumption is relatively highly weighted in the law of motion for habits, $1 / 2<\eta<\frac{1+\tau_{c}}{2-\tau_{l}+\tau_{c}}$, habits rise with an increase in either one of the parameters of habits strength in the utility. 
Table 1. $\quad$ Effects of Habits Parameters on Model 2 Responses.

\begin{tabular}{|c|c|c|c|c|c|c|}
\hline & \multicolumn{2}{|c|}{ Consumption } & \multicolumn{2}{|c|}{ Leisure } & \multicolumn{2}{|c|}{ Habits Stock } \\
\hline & $d \bar{C}$ & $d \bar{C} / d \tau_{c}$ & $d \bar{l}$ & $d \bar{l} / d \tau_{c}$ & $d \bar{h}$ & $d \bar{h} / d \tau_{c}$ \\
\hline$d \gamma>0$ & & & & & & \\
\hline$\eta<\frac{1+\tau_{c}}{2-\tau_{l}+\tau_{c}}$ & $(+)$ & $(+)$ & $(-)$ & $(-)$ & $(-)$ & $(-)$ \\
\hline$\eta>\frac{1+\tau_{c}}{2-\tau_{l}+\tau_{c}}$ & $(-)$ & NA & $(+)$ & NA & $(-)$ & NA \\
\hline$d \lambda>0$ & & & & & & \\
\hline$\eta<\frac{1+\tau_{c}}{2-\tau_{l}+\tau_{c}}$ & $(+)$ & $(-)$ & $(-)$ & $(+)$ & $(-)$ & $(-)$ \\
\hline$\eta>\frac{1+\tau_{c}}{2-\tau_{l}+\tau_{c}}$ & $(-)$ & $(+)$ & $(+)$ & $(-)$ & $(-)$ & $\begin{array}{l}\text { (+) if } \eta>1 / 2 \\
(-) \text { if } \eta<1 / 2\end{array}$ \\
\hline$d \eta>0$ & $(-)$ & NA & $(+)$ & NA & $\begin{array}{l}(+) \text { if } \frac{1+r \bar{B}}{2}>w \bar{l} \\
(-) \text { if } \frac{1+r \bar{B}}{2}<w \bar{l}\end{array}$ & NA \\
\hline
\end{tabular}

Note that the results shown in Table 1 can also be used to determine the relative depths of adjustment of consumption and leisure vis-à-vis each other under the two different policy changes. For example, consider the case of an increase in habits in the utility parameter $d \gamma>0$. When habits stock law of motion is strongly dominated by consumption,

$1 / 2<\eta<\frac{1+\tau_{c}}{2-\tau_{l}+\tau_{c}}$, habits will rise in response to an increase in the strength of habits parameter. At the same time consumption will rise and leisure will fall. The only way in 
which habits may increase in this case is when a fall in leisure expenditure is more than offset by a rise in consumption, i.e. whenever asset holdings of the households fall.

The results in Table 1 are driven by the combined assumptions of zero cross effects $\left(U_{c h}=U_{l h}=0\right)$, and zero second order effects $\left(U_{h h}=0\right)$ of habits. Under these assumptions, only direct effects of habits (disutility) matter. This allows us to flash out the importance of the relative weight of each component of the habits stock in determining which variable in the model will act as the main shock absorber. Hence, for sufficiently low $\eta$, consumption acts as the main variable absorbing changes in the habits parameters.

As shown in the Appendix 3, it is impossible to supply relative comparisons for the magnitude of the responses of model dynamics to changes in the habits parameters across the various tax policies.

\section{Conclusions.}

As mentioned in the introduction, the central feature of the traditional habits formation models is the exogeneity of labour supply decisions by the households. Following Boyer (1978), the vast majority of habit formation studies assume an inelastic supply of labour. As a result of this, traditional literature completely ignores both the direct effects of macroeconomic shocks on labour-leisure trade-off and the link between the effects of tax policy shocks on consumption and the presence of leisure in the optimisation set of the households.

Several recent papers touch upon the issue of endogenous labour supply in the presence of habits in consumption. Faria (2001) derives steady state solutions for leisure and consumption in a standard external habits model. However, his work does not provide an in depth discussion of the effects of the leisure-consumption trade-off on consumption adjustments. Furthermore, his work does not discuss the model's dynamics. Nor does Faria (2001) discuss the implications of endogenous labour supply in case of internal habits. Graham (2003) similarly extends the traditional habit formation model to include labour supply decisions. Using dynamic simulations he shows that under certain specific form assumptions, internal habit formation models perform less convincingly in the 
presence of endogenous labour supply than the standard habits models. Once again, the study lacks an analytical discussion of the model's dynamics.

To the best of our knowledge at present, no literature addresses the fundamental features of labour-consumption trade-off in household optimisation in the presence of an internal habit formation mechanism either in consumption alone, or in other components of the utility function.

Overall, our paper attempts to close several gaps. First we develop a model of internal habits in consumption in the presence of endogenous labour supply. Second, we provide comprehensive analysis of the present model's behaviour in response to changes in labour income and consumption tax policies. Third, we develop an entirely novel model of internal habits over the comprehensive set of choice variables in the model. In this case, habits are formed from both consumption and leisure. Fourth, we provide the same analysis of tax policy effects in the context of the comprehensive habits model, as in the case of the standard model of habits in consumption. Fifth, we provide a theoretical analysis of this model specification in the context of the robustness of our model of comprehensive habits. Sixth, we conclude by analysing the effect of habit formation parameters on the models behaviour for both the standard model of habit formation in the presence of endogenous labour supply and for the comprehensive habits model.

Following the rationale presented above, we first develop a model of habitual consumption decisions in the presence of endogenous labour supply. As expected, we analytically obtain the results similar to those in Graham (2003) numerical approximations. Furthermore, with respect to the effects of taxation changes, our benchmark model captures the results that mirror those established in the mainstream habit formation literature (e.g. Mansoorian, 1993). In the presence of habits in consumption alone, leisure acts as the main shock-absorbing variable, with discontinuous adjustments to the new steady state at the impact. Furthermore, in this setting, consumption tax is qualitatively equivalent to labour income tax. An increase in either one of the tax rates will result in the case of slow moving habits in downward overshooting in consumption, discrete increase in leisure and strengthening of the asset position by the households. In the case of fast moving habits, consumption incompletely adjusts downward at the impact, and continues to decline over time toward the new steady state, 
while leisure discretely rises. This implies that over time households reduce their financial wealth.

Following the results from the benchmark model, we proceed to develop a model in which habits are determined jointly by consumption and leisure. The main motivation for this exercise lies in the failure of the consumption-habit model to generate any persistence in labour supply. In addition, a simple extension of the traditional model to include endogenous labour supply, provided in Part 1, fails to generate any changes in the dynamics of the household consumption decisions relative to the benchmark models. For example, independent of the speed of habits stock adjustment to the new steady state, the model shows co-movement between consumption and labour supply. The reason for this is that habits in consumption imply that leisure and financial assets act as the main buffers in the households' response to exogenous shocks. Thus Model 1 fails to account for the possibility that consumption and leisure may co-move along the business cycle or in response to tax policy changes.

Model 2 introduces a new idea of comprehensive habits. Instead of basing a habitual standard of living on consumption history alone, we propose to model habits as evolving according to the law of motion specification that accounts for both real consumption and real leisure expenditure over time. This is precisely what we term comprehensive habits.

Intuitively, when consumers smooth both consumption and leisure, several forces determine their response to the exogenous shocks. First, they will substitute between consumption and labour supply as the main instruments for smoothing their intertemporal utility. Second, changes in the real after-tax wage will have different effects in such environments from changes in the real price of consumption. The latter has a stronger habit smoothing effect on consumption. In contrast, the former involves both substitution effects in leisure and the effect in terms of habit smoothing through the leisure component of habits. As agents substitute away from leisure, they also reduce the pressure of the negative effects of habits by lowering the impact of leisure in the habits stock. At the same time, since the speed of habits adjustment to the steady state is linked to the effects of habits on the marginal utility of consumption, marginal utility of consumption will be lower when the leisure component of comprehensive habits falls. This implies that agents may find it less costly to vary either leisure or consumption depending on the speed of 
habits adjustment relative to the responsiveness of the marginal utility of consumption to changes in habits stock.

As shown in Model 2, based on the speed of adjustment in habits relative to the importance of habits in the marginal utility of consumption, we can distinguish three environments.

In case A, households operate in the environment of fast moving habits. The habits stock adjusts to the new steady state at a rate that is above the rate of change in the marginal utility of income. Additionally, the high speed of adjustment in habits stock implies that the marginal utility of consumption is strongly influenced by changes in the habits stock.

As labour income tax increases, households, interested in maintaining a habitual standard of living, are more willing to use leisure as the main shock absorbing instrument over consumption. The result is to reduce leisure at the impact below the future lower steady state level. However, with the smoothing motive being strong, households will not adjust consumption to the sufficiently low levels required to offset a rise in leisure. Thus households will accumulate financial wealth along the adjustment path of rising leisure and falling consumption, as the habits stock co-moves with consumption. Note that alternatively case A can be interpreted as the case where consumption is relatively more important in determining the overall habits stock law of motion than the leisure expenditure.

A different situation arises in the case of an increase in the rate of consumption tax. Both consumption and leisure counter move. In this case, while smoothing motivation remains strong, consumers respond to a rise of the relative price of consumption induced by tax increase by lowering consumption short of the adjustment required to compensate households for an incomplete rise in leisure. This arises due to leisure becoming a stronger smoothing variable (relative to consumption) in response to consumption tax changes than in the case of labour income tax change. As the result, the households will draw down their stock of assets along the transition path.

In the case of slower adjusting habits (case B), the marginal utility of income grows faster than habits stock, while the overall effect of habits on the marginal utility of consumption remains relatively high. Then, in response to an increase in the labour income tax, consumption becomes the main instrument of smoothing whenever consumption 
dominates comprehensive habits relative to leisure $(\eta>1 / 2)$. The opposite occurs when leisure expenditure acts as the dominant determinant of habits stock $(\eta<1 / 2)$. Both leisure and consumption exhibit an incomplete adjustment to the new lower steady state in case of $\eta>1 / 2$. However, when leisure is dominant in comprehensive stock, both variables will overshoot the new steady states. Over time, consumption moves towards the new higher steady state, while labour supply moves to the new lower long run equilibrium level. This requires an increase in the households' financial wealth in the long run, and an overshooting of the higher steady state level at the impact by the comprehensive stock of habits.

In response to a change in consumption tax, the effects of tax policy shock differ from the case of changes in the labour income tax policy. Strong preferences for consumption smoothing (in the case of $\eta>1 / 2$ ) induced by the fast moving habits and relatively strong importance of consumption vis-à-vis leisure in the determination of the comprehensive habits stock imply that agents smooth consumption more in response to consumption tax change. Thus leisure now acts as a stronger shock absorber than consumption when the income effects of labour tax are replaced by the substitution effects of consumption tax. Hence, households decrease their labour supply (in contrast with the case of the response to the income tax increase discussed above), while simultaneously decreasing their consumption at the same time. The decrease in labour supply not is sufficiently strong to compensate for the lower consumption expenditure, so that along the adjustment path, savings rise and thus households accumulate financial assets.

Finally we consider the case of slowly adjusting habits combined with a relatively low effect of habits on the marginal utility of consumption (case C). By the assumption of separability, habits have no direct effect on the marginal utility of leisure. As a result, in response to changes in labour income tax, households continue to view leisure as the main smoothing component in the utility function, if leisure dominates consumption in the habits law of motion $(\eta<1 / 2)$. Then, consumption overshoots its higher steady state level at impact, while leisure falls down part of the way toward the new steady state level. Overtime, as consumption and leisure both fall, assets are drawn down to finance declining habits stock that overshoots its long run equilibrium level at the impact. The 
opposite effects occur if consumption dominates habits stock determination equation $(\eta>1 / 2)$.

In the case of consumption tax changes, as before, households view consumption as the main smoothing component, if $\eta<1 / 2$, allowing for only an incomplete downward adjustment in consumption. Leisure absorbs the shock at the impact and rises above the steady state level of demand. Overtime, a downward adjustment of leisure and consumption requires accumulation of the households' wealth along the adjustment path.

Hence, overall, in the case of both consumption and leisure contributing to the habit stock, consumption and labour income taxes are no longer qualitatively equivalent in their effects on the household decisions. As shown in this paper, differences in households' responses to different tax policies depend on the environment described by the speed of habits adjustment to the steady state relative to the effect of habits on both the marginal utility of income and the marginal utility of consumption. In some cases, labour supply changes procyclically with changes in consumption, while in other cases, leisure changes reinforce adjustments in consumption. This implies that labour supply and consumption countermove and that the degree of this counter movement may depend on the habit formation parameters of the model.

Similarly, the asset positions of the households can either be procyclical with consumption changes or counter-cyclical in the presence of comprehensive habits. This result does not hold in the traditional model of habit formation in consumption.

Furthermore, in all cases in the presence of comprehensive habits, leisure follows a gradual adjustment path. The speed of adjustment, as well as the depth of changes in each variable of interest, varies across various environments and tax policies. The singular prediction of the traditional model of habits in consumption in the presence of endogenous labour supply is that consumption will exhibit excess smoothening, thus failing to capture an empirically plausible degree of variation along the adjustment path. This prediction breaks down in the case of comprehensive habits.

As shown in our model, comprehensive habits introduce time dependency into both consumption and leisure decisions of the households. This implies that depending on the model parameters both consumption and leisure may overshoot their targets. The implied 
volatility of consumption around the steady state in our model is thus subject to more variation than in the traditional models of habit formation. Such simultaneous smoothing of leisure and consumption is robust to relaxing several major assumptions concerning the household preferences. Specifically, as shown in part 3 of this study, both main variables of choice will exhibit a persistent tendency to deviate from their long-run equilibrium levels even in the absence of habits effects on the marginal utilities of consumption and leisure. In addition, relaxing assumption of the negative second order effect of habits on the marginal disutility of habits retains this important result. 


\section{Bibliography.}

Abel, A. "Asset Prices under Habit Formation and Catching up with the Joneses".

The American Economic Review, V80, Issue 2 (May 1990), pages 38-42

Aguiar, M. and Hurst, E. "Consumption vs. Expenditure” NBER Working Paper 10307, February 2004.

Barro, R. and King, R. "Time Separable Preferences and Intertemporal Substitution Models of Business Cycles", Quarterly Journal of Economics, 99, 1984., pages 817-839.

Becker, G. "A Theory of Allocation of Time”, Economic Journal, 75 (299), 1965, pages 493-508.

Becker, G., Murphy, K., and Werning, I. "Status, Lotteries and Inequality”, Manuscript, University of Chicago, May 2000.

Boyer, M. “A Habit Forming Optimal Growth Model”, International Economic Review, Vol. 19 (3) pp. 585-609.

Carliner, G. "Wages, Earnings and Hours of First, Second and Third Generation American Males”, Economic Inquiry 18, January 1980, pages 87-102

Carroll, C., Overland, J., and Weil, D. "Comparison Utility in a Growth Model”, Manuscript, 1994.

Carroll, C. "Solving Consumption Models with Multiplicative Habits", Manuscript, Johns Hopkins University, 2000

Caves, R., Frankel, J., and Jones, R. "World Trade and Payments", $6{ }^{\text {th }}$ edition. Harper Collins College Publishers, 1993, pages 180-181

Chamley, C. "Optimal Taxation of Capital Income in General Equilibrium with Infinite Lives”, Econometrica, 54, May 1986, pages 607-622.

Chiang, A. "Fundamental Methods of Mathematical Economics", 3 rd edition, McGrawHill International Editions, 1998, pages 605-647.

Chiswick, B. "Immigrants and Immigration Policy", in Contemporary Economic Problems, ed. William Fellner (Washington D.C.: American Enterprise Institute, 1978), pages 285-325.

Constantinides, G. "Habit Formation: A Resolution of the Equity Premium Puzzle", The Journal of Political Economy, V.98, Issue 3, 1990, pages 519-543.

Deaton, A. and Muellbauer, J. "Economics and Consumer Behaviour", Cambridge University Press, 1996, pages 127-145 
Dynan, K. "Habit Formation in Consumer Preferences: evidence from Panel Data", Amercian Economic Review, vol.90, June 2000, pages 391-406. Referenced to 1999 manuscript version is referred in the text.

Ehrenberg, R., and Smith, R. "Modern Labour Economics" $5^{\text {th }}$ edition, Harper Collins College Publishers, 1994, pages 330-339 and 353-358

Engel, C. and Kletzer, K. "Tariffs and savings in a model with new generations", Journal of International Economics, 28, 1990, pages 71-91.

Faria, J. "Growth and labor supply in the presence of habit formation in consumption" Political Economy Working Paper 05/01, School of Social Sciences, University of Texas at Dallas, 2001.

Fuhrer, J. "Habit Formation in Consumption and its Implications for the Monetary Policy Models”, The American Economic Review, forthcoming. 1999.

Gali, J. , "Keeping Up with the Joneses: Consumption Externalities, Portfolio Choice and Asset Prices", Journal of Economic Theory, vol 63, no.1, 1994, pages 73-96.

Graham, L. "Some macroeconomic effects of habit formation in consumption", Manuscript, University of Warwick, 2003.

Gurdgiev, C. "Life-Cycle Model of Leisure Demand with Habit Formation", Manuscript, Trinity College, Dublin, Department of Economics, 2003.

Hansen, G., and Wright, R. "The Labor Market in Real Business Cycle Theory", Federal Reserve Bank of Minneapolis Quarterly Review, Spring 1992.

Ikeda, S. "Tariffs, Time Preference, and the Current Account under Weakly Nonseparable Preferences", The Institute of Social and Economic Research, Osaka University, Discussion Paper Number 519, October 2000

Jones, L., Manuelli, R., and Rossi, P. “Optimal Taxation in Models of Endogenous Growth", Journal of Political Economy, 101, June 1993, pages 485-517.

Judd, K. "Redistributive Taxation in a Simple Perfect Foresight Model”, Journal of Public Economics, 28, October 1985, pages 59-84.

Kozlowski, O., P. Pintus, S. van Strien and R. de Vilder, "Business Cycle Models: closing the gap between the different approaches" University of Warwick, manuscript, December 2001.

Mansoorian, A. "Habit Persistence and the Harberger-Laursen-Metzler effect in an infinite horizon model”, Journal of International Economics, November 1993, pages $153-166$. 
Mansoorian, A. "Tariffs, habit persistence and the current account", Canadian Journal of Economics, XXVI, Number 1, 1993, pages 194-207.

Mansoorian, A. "On the Macroeconomic Policy Implications of Habit Persistence", Journal of Money, Credit and Banking, Volume 28, No. 1, 1996, pages 119-129.

Mendoza, E., Milesi-Ferretti, G., and Asea, P. "On the Effectiveness of Tax Policy in Promoting Long-Run Growth: Harberger's Superneutrality Conjecture", CEPR Discussion Paper, Number 1378, 1996-1997.

McConnell, Campbell, R. and Brue, S. "Contemporary Labour Economics”, McGrawHill, Inc. NY, NY, $4^{\text {th }}$ edition, 1995 pages $254-280$

Milesi-Ferretti, G. and Roubini, N. "Growth Effects of Income and Consumption Taxes", Journal of Money, Credit and Banking, 30(4), November 1998, pages 721-744.

Muellbauer, J. "Habits, Rationality and Myopia in the Life-Cycle Consumption Function", Annals of Economics and Statistics, 9, 1988, pages 47-70.

Razin, A. and Svensson, L. "Trade Taxes and the Current Account", Economic Letters, 13 , pages $55-57$

Ryder, H. and Heal, G. "Optimal Growth with Intertemporally Dependent Preferences", Review of Economic Studies, 40, 1973, pages 1-31.

Sen, P. and Turnovsky, S. "Tariffs, Capital Accumulation, and the Current Account in a Small Open Economy", International Economic Review, 30, 1989, pages 227250.

Sui, S. "Weakly Nonseparable Preferences and Distortionary Taxes in a Small Open Economy”, International Economic Review, Vol.35 No. 2, May 1994, pages 411-428.

Varian, R. "Microeconomic Analysis" $2^{\text {nd }}$ edition, W.W. Norton\&Company, 1984, Chapter 3.6, pages 126-128 


\section{Appendix 1. Mathematical Solutions for Model 1.}

Here we want to derive the solutions used in the discussion of Model 1 that extends the standard analysis of habits in consumption to explicitly incorporating endogenous leisure demand and consumption/leisure trade-offs by the households.

We begin with the first order conditions for the household optimisation program defined in equation (7). The first order conditions with respect to consumption, habits, leisure and asset position of the household are given in the text under equations (8)-(12). Equation (13) follows from applying conditions (12) to (11) and substituting into the log-linearised version of the first-order condition (10).

To derive equations (14)-(15), linearise equations (6), (9) and (8) around the steady state. Making use of result (12):

$$
\begin{aligned}
& \dot{h}_{t}=\lambda[C-\bar{C}]-\lambda[h-\bar{h}] \\
& \dot{\xi}_{t}=-U_{h C}[C-\bar{C}]-U_{h h}[h-\bar{h}]+(r+\lambda)[\xi-\bar{\xi}] \\
& U_{C C}[C-\bar{C}]+U_{C h}[h-\bar{h}]=-\lambda[\xi-\bar{\xi}]
\end{aligned}
$$

Solve (A.1.3) for the deviation in consumption, then substitute into the linearised laws of motion (A.1.1) and (A.1.2) to obtain equations (14) and (15) in the text.

Looking at the determinant of matrix $A$,

$$
\operatorname{det} A=-\lambda\left[\frac{\left(U_{C h}+U_{C C}\right)\left(\lambda U_{C h}+(\lambda+r) U_{C C}\right)}{U_{C C}^{2}}\right]+\frac{\lambda^{2}\left(U_{C h}^{2}-U_{C C} U_{h h}\right)}{U_{C C}^{2}}<0
$$

Under the standard Ryder-Heal assumptions (4), we are guaranteed the existence of the negative eigen-value of matrix $A$, given by equation (16). From the determinant of $A$ in equation (A.1.4) and by equation (16):

$-\phi>;<\lambda$ if and only if $-\frac{U_{h h}}{U_{C h}}>;<\frac{2 \lambda+r}{\lambda}$.

This yields inequalities (17) in the text. Since we assume, as standard that habits are nonaddictive, $U_{h h}<0$. 
Note that this condition is satisfied for the traditional group of CRRA utility specifications commonly employed in the models of habit formation in consumption as long as the intertemporal elasticity of substitution parameter is no lower than 3 (see, for example Carroll, Overland and Weil, 1994). It also satisfies extension of the model by Faria (2001) which includes the endogenous supply of labour. Furthermore, these inequalities apply to our specific solutions presented in the Appendix 3 below.

From the standard solutions to the system of equations given in equations (14) and (15), we have equations (18) and (19) in the text. Then linearising equation (3) around the steady state and using equation (1) to substitute for tax rebate, we have, after applying condition (13):

$$
\dot{B}_{t}=r(B-\bar{B})-[C-\bar{C}]
$$

Substitute equations (18) and (19) into equation (A.1.3) to get:

$$
\begin{aligned}
{[C-\bar{C}] } & =\left[-\frac{U_{C h}}{U_{C C}}-\frac{\lambda}{U_{C C}} \frac{\phi-a_{11}}{a_{12}}\right]\left(h_{0}-\bar{h}\right) e^{\phi t}= \\
& =\left[-\frac{U_{C h}}{U_{C C}}+\frac{U_{C C} \phi+\lambda\left(U_{C C}+U_{C h}\right)}{\lambda U_{C C}}\right]\left(h_{0}-\bar{h}\right) e^{\phi t}
\end{aligned}
$$

Substitute equation (A.1.5) into the preceding equation to get equation (20) in the text.

Standard solution to equation (20) is given by:

$$
\begin{aligned}
& (B-\bar{B})=\frac{\Omega}{\phi-r}\left(h_{0}-\bar{h}\right) e^{\phi t}+\mathrm{P} \\
& \mathrm{P}=\left[\left(B_{0}-\bar{B}\right)-\frac{\Omega}{\phi-r}\left(h_{0}-\bar{h}\right)\right] e^{r t}
\end{aligned}
$$

To obtain the steady state we set $\overline{\mathrm{P}} \equiv 0$ which implies equation (21) and from which equation (22) follows trivially.

To solve the system of equations given by (22)-(26): first observe that by the first order condition (10):

$$
\bar{\mu}=\frac{U_{l}}{w(1-\tau)}
$$

while by differentiating the budget constraint at the steady state we get equation (23) in the text. 
Differentiating equations (9) and (12) we have:

$d \bar{C}=-\frac{U_{h h}}{U_{C h}} d \bar{h}+\frac{\lambda+r}{U_{C h}} d \bar{\xi}$

$d \bar{C}=d \bar{h}$

which, combined, yield equation (24) in the text. Differentiating equation (9) and using result (A.1.8) yields equation (26). Equation (25) follows from differentiating the firstorder condition (10). By combining equations (24) and (26) and re-arranging we obtain equation (27).

\section{Consumption Tax Change.}

To derive the response of choice variables to a one time permanent increase in consumption tax, first substitute equation (28) into (27) and solve for the effect of the consumption tax on the steady state value of habits stock, using condition (A.1.8) above:

$$
\frac{d \bar{h}}{d \tau_{C}}=\frac{d \bar{C}}{d \tau_{C}}=\frac{U_{l}}{w\left[U_{C C}+U_{C h}\left(\frac{2 \lambda+r}{\lambda}\right)+U_{h h}\right]}<0
$$

Setting equation (23) equal to equation (22), we get an expression for a change in the steady state value of leisure demand due to change in consumption tax as a function of changes in the habits stock:

$$
\frac{d \bar{l}}{d \tau_{C}}=\left(\frac{r \Omega}{\phi-r}-1\right) \frac{d \bar{h}}{d \tau_{C}}
$$

Using result (29) in equation (A.1.9) we get equation (30) in the text. Finally equation (31) follows from equations (22) and (29).

To analyse the case of choice variables changes along the adjustment path and at impact, we consider two cases defined in (31). This follows directly from the Mansoorian (1993) approach. First note that by equations (6) and (18) at the steady state:

$\frac{C_{0}^{+}-h_{0}}{\bar{h}-h_{0}}=-\frac{\phi}{\lambda}$ 
Hence in case 1: $\frac{C_{0}^{+}-h_{0}}{\bar{h}-h_{0}}=-\frac{\phi}{\lambda}>1$ which implies that $C_{0}^{+}<\bar{h}$ so that at the impact, consumption downward overshoots the new lower steady state level of habits. At the same time, the reverse applies in case 2 so the are no overshooting results. This establishes the dynamics of consumption at the impact. The dynamics of leisure are given by conditions (13) and (30).

\section{Labour Income Tax Change.}

Finally, the equivalent result between consumption and labour income tax changes follows from the following. By equation (25), using result (28):

$$
\frac{d \bar{l}}{d \tau_{l}}=-\frac{U_{l}}{U_{l l}\left(1-\tau_{l}\right)}>0
$$

By equations (23) and (22):

$$
\frac{d \bar{h}}{d \tau_{l}}=-\frac{(\phi-r) \lambda}{\phi(r+\lambda)} \frac{d \bar{l}}{d \tau_{l}}=\frac{d \bar{C}}{d \tau_{l}}<0
$$

The dynamics of the household's asset position follow from equation (22). Hence, the effects of a one time permanent increase in the rate of labour income taxation are identical to the effects of an increase in the consumption tax, at least qualitatively. This implies that all variables of choice will respond in the same direction under both tax policy changes. 


\section{Appendix 2. Mathematical Solutions for Model 2.}

Here we derive the solutions used in discussion of the model with comprehensive habits, Model 2, that extends the possibility of past history dependence to both consumption and leisure demand by the households.

We begin with the first order conditions for the household's optimisation, given in the text under equations (35)-(38). From (38) it follows that (12) holds.

$$
\delta=r \Leftrightarrow \dot{\mu}_{t}=0
$$

To derive equations (39) and (40), as in Model 1 above, we first linearise equations (35)(37), and (32) around the steady state:

$$
\begin{aligned}
& U_{C C}(C-\bar{C})=-U_{C h}(h-\bar{h})-\lambda_{c} \eta(\xi-\bar{\xi}) \\
& \dot{h}_{t}=\lambda_{c} \eta[C-\bar{C}]+\lambda_{c}(1-\eta) w[l-\bar{l}]-\lambda_{c}[h-\bar{h}] \\
& \dot{\xi}_{t}=-U_{C h}[C-\bar{C}]-U_{h h}[h-\bar{h}]+\left(r+\lambda_{C}\right)[\xi-\bar{\xi}] \\
& U_{l l}[l-\bar{l}]=-\lambda_{C}(1-\eta) w[\xi-\bar{\xi}]
\end{aligned}
$$

Solve (A.2.5) for deviation in leisure demand, then substitute into (A.2.3) and (A.2.4) to obtain

$$
\begin{aligned}
& \dot{h}_{t}=-\lambda_{c}\left[\frac{\eta U_{c h}+U_{c c}}{U_{c c}}\right](h-\bar{h})-\lambda_{c}^{2}\left[\frac{\eta^{2} U_{l l}+(1-\eta)^{2} w^{2} U_{c c}}{U_{c c} U_{l l}}\right](\zeta-\bar{\zeta}) \\
& \dot{\zeta}_{t}=\left[\frac{U_{c h}^{2}-U_{h h} U_{c c}}{U_{c c}}\right](h-\bar{h})+\left[\frac{\lambda_{c} \eta U_{c h}+\left(\lambda_{c}+r\right) U_{c c}}{U_{c c}}\right](\zeta-\bar{\zeta})
\end{aligned}
$$

Equations (39) and (40) in the text follow, as does equation (41).

Looking at the determinant of $A$, under the assumptions on preferences given in (4) and (33), we are guaranteed the existence of the negative eigenvalue. However, condition (17) no longer applies in Model 2. Instead, from the negative of the determinant given by

$$
\begin{aligned}
-\operatorname{det} A_{2}= & \lambda_{c}\left[\frac{\eta U_{c h}}{U_{c c}}+1\right]\left[r+\lambda_{c}+\lambda_{c} \frac{\eta U_{c h}}{U_{c c}}\right]- \\
& -\lambda_{c}^{2}\left[U_{c h}^{2}-U_{h h} U_{c c}\right]\left[\eta^{2} U_{l l}+(1-\eta)^{2} w^{2} U_{c c}\right]
\end{aligned}
$$


it is a straightforward exercise to show that (42) must hold. Unlike in Model 1, condition (42) defines the relationship between $\lambda_{c}$ and the marginal utility of consumption effect of habits, $\phi_{c}$ only in implicit terms. The reason for this is that the right hand side of (42) can be either positive or negative, depending on whether

$$
w^{2}(1-\eta)^{2}\left[U_{C h}^{2}-U_{C C} U_{h h}\right]<,>\eta^{2} U_{h h} U_{l l} \text {. }
$$

This depends on whether the real effect of habits on the marginal utility of $C_{t}$ (net of the own marginal utility second order effects of $C_{t}$ ) is weak or strong relative to the second order effects of habits on the marginal disutility of habits and the marginal utility of leisure. In addition, it also depends on whether the second order effects of habits on their disutility is weak or strong relative to the same second order effects of habits.

Alternatively, (42) depends on the relative weight of consumption in habits, parameter $\eta$. The underlying assumption in this context is that $2 U_{c h}+\eta U_{h h}<0$. This assumption, by the analogy with Mansoorian (1993) corresponds to the requirement that taxes are nondistortionary.

The standard solution to the system (39)-(40) for habits stock is:

$$
(h-\bar{h})=\left(h_{0}-\bar{h}\right) e^{\phi t}
$$

Then, from (39),

$$
(\xi-\bar{\xi})=-\frac{U_{l l} U_{C C}\left(\phi_{c}+\lambda_{c}\right)}{\lambda_{c}^{2}\left[\eta^{2} U_{l l}+(1-\eta)^{2} w U_{C C}\right]}\left(h_{0}-\bar{h}\right) e^{\phi t}
$$

Linearising budget constraint (3) using transfer identity (1), after substituting (A.2.9) and (A.2.10) above we have, as in Model 1, equation (43). Condition (44) and equation (45) trivially follow from this and (42) as derived in the Appendix 1.

\section{Tax Policy Change: General Solution.}

We already outlined how equation (45) is determined. To obtain equation (46), observe that

$$
B-\bar{B}=\frac{\Omega_{2}}{\phi_{c}-r} e^{\phi t}\left(h_{0}-\bar{h}\right)+\mathrm{P}_{t}
$$


where

$\mathrm{P}_{t}=\left[\left(B_{0}-\bar{B}\right)-\frac{\Omega_{2}}{\phi_{c}-r}\left(h_{0}-\bar{h}\right)\right] e^{r t}$

Hence, the steady state requires that $\overline{\mathrm{P}}=0$. Equation (46) then follows directly from these.

Equations (47)-(49) are derived as follows: first we differentiate equations (35)-(37) and (3) and (32) using (1). This yields

$$
\begin{aligned}
& 0=\eta d \bar{C}+w(1-\eta) d \bar{l}-d \bar{h} \\
& d \bar{T}=w(1-\bar{l}) d \tau_{l}-w \tau_{l} d \bar{l}+\bar{C} d \tau_{C}+\tau_{C} d \bar{C} \\
& 0=r d \bar{B}-w d \bar{l}-d \bar{C} \\
& U_{C C} d \bar{C}+U_{C h} d \bar{h}=\bar{\mu} d \tau_{C}-\lambda_{c} \eta d \bar{\xi} \\
& U_{l l} d \bar{l}=-\bar{\mu} w d \tau_{l}-\lambda_{c}(1-\eta) w d \bar{\xi} \\
& -U_{h h} d \bar{h}-U_{C h} d \bar{C}+\left(\lambda_{c}+r\right) d \bar{\xi}=0
\end{aligned}
$$

Evaluate (35) and (37) at the steady state and solve for $\bar{\mu}$ to obtain

$$
0<\bar{\mu}=\frac{U_{C}}{1+\tau_{C}}-\frac{\lambda_{c} \eta U_{h}}{\left(1+\tau_{C}\right)\left(\lambda_{c}+r\right)}=\frac{U_{l}}{1-\tau_{l}}-\frac{\lambda_{c} w(1-\eta) U_{h}}{\left(1-\tau_{l}\right)\left(\lambda_{c}+r\right)}
$$

Next use (A.2.13) in (A.2.16) and (A.2.18). and note that by the law of motion for habits, $d \bar{C}=\frac{1}{\eta}(d \bar{h}-(1-\eta) w d \bar{l})$

This yields a system of three equations:

$$
\begin{aligned}
& \frac{U_{c c}}{\eta} d \bar{h}-\frac{U_{c c}(1-\eta) w}{\eta} d \bar{l}=\bar{\mu} d \tau_{c}-\lambda_{c} \eta d \bar{\zeta} \\
& U_{l l} d \bar{l}=-\bar{\mu} w d \tau_{l}-\lambda_{c}(1-\eta) w d \bar{\zeta} \\
& -\left(U_{h h}+\frac{U_{c h}}{\eta}\right) d \bar{h}+\frac{U_{c h}(1-\eta) w}{\eta} d \bar{l}+\left(\lambda_{c}+r\right) d \bar{\zeta}
\end{aligned}
$$

Using (A.2.17) the above system can be reduced to: 


$$
\begin{aligned}
& \frac{U_{c c}}{\eta} d \bar{h}=\bar{\mu} d \tau_{c}+\frac{\bar{\mu} \eta}{(1-\eta)} d \tau_{l}+\frac{U_{c c}(1-\eta)^{2} w^{2}+\eta^{2} U_{l l}}{\eta(1-\eta) w} d \bar{l} \\
& -\left(U_{h h}+\frac{U_{c h}}{\eta}\right) d \bar{h}+\frac{U_{c h}(1-\eta)^{2} w^{2} \lambda_{c}-\eta\left(\lambda_{c}+r\right) U_{l l}}{\eta \lambda_{c}(1-\eta) w} d \bar{l}=\frac{\bar{\mu}\left(\lambda_{c}+r\right)}{\lambda_{c}(1-\eta)} d \tau_{l}
\end{aligned}
$$

Equation (51) follows from the system (A.2.22) by solving the last equation for change in the steady state value of leisure and substituting the result into the first equation. To obtain equation (47) and definitions (48)-(50), substitute (51) into the first equation in system (A.2.22) to obtain

$$
\begin{aligned}
& \frac{U_{c c}}{\eta} d \bar{h}=\bar{\mu} d \tau_{c}+\frac{\eta \bar{\mu}}{(1-\eta)} d \tau_{l}+ \\
& +\frac{\eta^{2} U_{l l}+(1-\eta)^{2} w^{2} U_{c c}\left[\left(\eta w\left(\lambda_{c}+r\right) \bar{\mu}\right) d \tau_{l}+\left(\lambda_{c}(1-\eta) w\left(\eta U_{h h}+U_{c h}\right)\right) d \tau_{c}\right]}{\eta(1-\eta) w\left[(1-\eta)^{2} w^{2} \lambda_{c} U_{c h}-\eta\left(\lambda_{c}+r\right) U_{l l}\right]}
\end{aligned}
$$

Equation (A.2.23) reduces to (47)-(50). Equation (51) was derived earlier.

\section{Specific Tax Policy Changes.}

To solve for the effects of labour income tax change, set $d \tau_{c}=0<d \tau_{l}$ in the above equations. Equation (52) in the text follows directly from equation (47) in the text. Equation (53) was discussed above in details. By equation (51) in the text, equation (54) follows trivially. Finally, condition (55) is derived from the definition of habits stock in the steady state and equation (A.2.20) above. The latter is related to condition (56). Inequalities (57) are direct solutions for the sign of (56).

Dynamics of the system follow from the standard approach introduced in Model 1. First observe that:

$0<-\frac{\phi_{c}}{\lambda_{c}}=\frac{\eta C_{0}^{+}+w(1-\eta) l_{0}^{+}-h_{0}}{\bar{h}-h_{0}}=\frac{h_{0}^{+}-h_{0}}{\bar{h}-h_{0}}<;>1 \quad$ iff case $A$; cases $B$ and $C$.

\section{In case $\mathbf{A}$ :}

$\eta \underbrace{C_{0}^{+}}_{\uparrow}+(1-\eta) w \underbrace{l_{0}^{+}}_{\downarrow}<\underbrace{\bar{h}}_{\uparrow}$ 
$\eta C_{0}^{+}+(1-\eta) w l_{0}^{+}>h_{0}$

$\eta \bar{C}+(1-\eta) w \bar{l}>h_{0}$

This implies that no overshooting will result in either leisure demand or consumption, but not in habits stock. From the law of motion for the asset stock:

$$
\begin{aligned}
& \dot{B}_{t}-\dot{\bar{B}}=\dot{B}_{t}=r\left(B_{0}^{+}-\bar{B}\right)+w\left(\bar{l}-l_{0}^{+}\right)-\left(C_{0}^{+}-\bar{C}\right)>0 \\
& \dot{B}_{t}^{+}-\dot{B}_{t}=-r\left(B_{0}^{+}-B_{t}\right)+w\left(l_{t}-l_{0}^{+}\right)-\left(C_{0}^{+}-C_{t}\right)<0
\end{aligned}
$$

The only adjustment path for leisure, consistent with the above conditions involves downward overshooting at the impact followed by a rise in leisure demand to the new lower steady state level.

In case B:

$$
\begin{aligned}
& \eta \underbrace{C_{0}^{+}}_{\uparrow}+(1-\eta) w \underbrace{l_{0}^{+}}_{?}>\underbrace{\bar{h}}_{\uparrow} \\
& \eta \bar{C}+(1-\eta) w \bar{l}>h_{0} . \\
& \eta C_{0}^{+}+(1-\eta) w l_{0}^{+}>h_{0} .
\end{aligned}
$$

At the same time, agents will save over the adjustment path. From the budget constraint (law of motion for the asset stock):

$$
\left(C_{0}^{+}-\bar{C}\right)\left[\frac{1-2 \eta}{\eta}\right]>r\left(B_{0}^{+}-\bar{B}\right)
$$

The only way this can occur is if consumption overshoots its long run steady state level whenever $\eta>1 / 2$, in which case leisure adjusts incompletely to the steady state at the impact. Alternatively, if $\eta<1 / 2$ consumption adjusts incompletely at the impact, while leisure overshoots its long run equilibrium level downward (from below).

\section{In case $C$ :}

$$
\begin{aligned}
& \eta \underbrace{C_{0}^{+}}_{?}+(1-\eta) w \underbrace{l_{0}^{+}}_{?}>\underbrace{\bar{h}}_{\uparrow} \\
& \eta C_{0}^{C_{0}^{+}}+(1-\eta) w l_{0}^{+}>h_{0}
\end{aligned}
$$

and from the law of motion for assets:

$$
\operatorname{\eta r}\left(B_{0}^{+}-\bar{B}\right)>w(1-2 \eta)\left(\bar{l}-l_{0}^{+}\right)
$$


This implies that since over the long run, agents accumulate savings. Consumption must initially overshoot the long run steady state level whenever $\eta<1 / 2$. The rest of dynamics follows as earlier.

Similar exercise provides results in the case of changes in the consumption tax rate. 


\section{Appendix 3. Mathematical Solutions for Specific Choice of the Utility Function With Separable Habits and in Absence of Second Order Effects (Part 3).}

Here we derive the solutions for Model 2 in the context of specific assumptions on the form of the utility function discussed in part 3 in the text.

Assume that instantaneous utility function is separable across habits:

$U\left(C_{t}, l_{t}, h_{t}\right)=\log \left(C_{t}\right)+k \log \left(l_{t}\right)-\gamma h_{t}$

where

$\dot{h}_{t}=\lambda_{c}\left(\eta C_{t}+(1-\eta) w l_{t}-h_{t}\right)$

and in the steady state:

$h_{s s}=\eta C_{s s}+(1-\eta) w l_{s s}$

The specification (A.3.1) is consistent with assumptions in (4) and (33) with exception of $U_{C h}=U_{l h}=U_{h h}=0$. This implies that due to separability assumption on habits, habits stock does not have a direct effect on the marginal utility of consumption and the marginal utility of leisure. The violation of these assumptions represents a major departure in this model from the general models discussed in parts 1 and 2 of the paper. The cross effects of habits on the marginal utility of consumption in the mainstream models imply that the marginal utility of consumption is increasing in the habits stock. This, in turn moderates the second order effects of consumption and leisure as can be seen from equations (15) and subsequent analysis of both models. The result is that under the assumption of fully separable habits in the utility function, the model results reflect solely the second order effects of consumption and leisure choices and only the first order effects of habits. The latter reinforce the former without the partially offsetting moderation of the cross effects.

From the first order conditions,

$$
\begin{aligned}
& C_{t}-\bar{C}=\lambda_{c} \eta C_{t}^{2}\left(\zeta_{t}-\bar{\zeta}\right) \\
& l_{t}-\bar{l}=\frac{(1-\eta) w \lambda_{c} l_{t}^{2}}{k}\left(\zeta_{t}-\bar{\zeta}\right)
\end{aligned}
$$

and thus 
$l_{t}-\bar{l}=\frac{(1-\eta) w l_{t}^{2}}{k \eta C_{t}^{2}}\left(C_{t}-\bar{C}\right)$

From the definition of matrix $A$,

$$
\begin{array}{ll}
a_{11}=-\lambda_{c} & a_{12}=\frac{\lambda_{c}^{2}}{k}\left[\eta^{2} k C_{t}^{2}+(1-\eta)^{2} w^{2} l_{t}^{2}\right] \\
a_{21}=0 & a_{22}=r+\lambda_{c}
\end{array}
$$

so that

$-\phi_{c}=\lambda_{c} \quad \Leftrightarrow \quad \Omega_{c}=0$

Condition (A.3.7) implies that along the adjustment path adjustment speed of all variables is identical to the adjustment speed of habits stock. This is the result of the absence of second order effects of habits in the utility function that replicates the exogenous nature of habits under the assumptions in this present model. In return this implies that along the adjustment path

$$
\dot{B}_{t}=r\left(B_{t}-\bar{B}\right)
$$

and for the steady state deviations:

$d \bar{B}=0$

Also along the adjustment path

$$
\left(h_{t}-\bar{h}\right)=\left(h_{t}-h_{0}\right) \exp \left(-\lambda_{c} t\right)
$$

so that

$$
d \bar{h}=(2 \eta-1) d \bar{C}
$$

By equations (A.2.19), under our assumptions:

$$
\bar{\mu}=\frac{1}{\bar{C}\left(1+\tau_{c}\right)}+\frac{\gamma \lambda_{c} \eta}{\left(\lambda_{c}+r\right)\left(1+\tau_{c}\right)}=\frac{1}{w\left(1-\tau_{l}\right)}\left[\frac{k}{\bar{l}}-\frac{\lambda_{c}(1-\eta) \gamma w}{\left(\lambda_{c}+r\right)}\right]
$$

From within the law of motion for assets stock, in the steady state:

$$
w(1-\bar{l})+r \bar{B}=\bar{C}=w(1-\bar{l})+r B_{0}
$$

Hence,

$$
d \bar{l}=-\frac{1}{w} d \bar{C}=-\frac{w \bar{\mu}}{U_{l l}} d \tau_{l}
$$




\section{Consumption Tax Policy.}

Set $d \tau_{c}>0=d \tau_{l}$.

$$
\frac{d \bar{l}}{d \tau_{c}}=\frac{\bar{C}\left(w-\bar{C}+r B_{0}\right)(1-\eta) \eta\left(\lambda_{c}+r+\gamma \lambda_{c} \eta \bar{C}\right)}{\left(1+\tau_{c}\right)\left(\lambda_{c}+r\right) w\left[\eta^{2} k \bar{C}^{2}+(1-\eta)^{2} \frac{\left(w-\bar{C}+r B_{0}\right)^{2}}{w^{2}}\right]}>0
$$

By (A.3.9):

$$
\begin{aligned}
& \frac{d \bar{C}}{d \tau_{c}}=-w \frac{d \bar{l}}{d \tau_{c}}<0 \\
& \frac{d \bar{h}}{d \tau_{c}}=-(2 \eta-1) \frac{d \bar{C}}{d \tau_{c}}>;<0 \quad \Leftrightarrow \quad \eta>;<1 / 2
\end{aligned}
$$

Finally,

$0<-\frac{\phi_{c}}{\lambda_{c}}=1=\frac{h_{0}^{+}-h_{0}}{\bar{h}-h_{0}}$

Hence, by (A.3.18):

$h_{0}^{+}=\bar{h}>h_{0} \quad \Leftrightarrow \quad \eta>1 / 2$

$h_{0}^{+}=\bar{h}<h_{0} \quad \Leftrightarrow \quad \eta<1 / 2$

Hence, if $\eta>1 / 2$, habits stock increases at the impact to its new steady state level, while consumption falls part of the way to the new steady state level. At the same time, leisure increases to an impact level that is below the long run equilibrium. Habits stock jumps, at the impact, to the new and higher steady state level, so that at the impact, change in consumption is smaller in the absolute value than in the leisure expenditure. The only way this can happen is when asset holdings fall at the impact. Along the adjustment path, leisure rises, consumption falls, and asset stock rises, while habits remain at their new steady state level.

When $\eta<1 / 2$, habits stock falls at the impact to the lower steady state level.

Consumption falls, while leisure rises. At the impact, consumption fall is greater in the absolute value than the rise in the leisure expenditure, so that asset position jumps up to 
reflect the achieved savings. Overtime, as positive increase in financial wealth is drawn down, leisure continues to rise, while consumption continues to fall.

Note that in both cases, adjustments require no overshooting, while both consumption and leisure are being smoothed. The degree of smoothing is driven solely by the importance of each component in the determination of comprehensive habits. When consumption dominates habits law of motion, $\eta>1 / 2$, at the impact adjustment in consumption are smaller than adjustment in leisure. In terms of our discussion of model 2, this occurs because consumption acts as the main smoothing variable.

Figure 9 illustrates model adjustments in case of consumption and labour income tax changes. The discontinuous and complete nature of the habits stock adjustment at the impact is of interest in the context of the recent evidence, provided by Aguiar and Hurst (2004), as discussed in part 3.

\section{Effects of Habits Parameters on Choice Variables.}

To determine the effects of habits parameters on the model dynamics, consider the first order conditions for Model 2, under the assumption (A.3.1):

$$
\begin{aligned}
& \frac{1}{\bar{C}}=\left(1+\tau_{c}\right) \bar{\mu}-\lambda_{c} \eta \bar{\zeta} \\
& -\frac{k}{\bar{l}}+\left(1-\tau_{l}\right) w \bar{\mu}=(1-\eta) w \lambda_{c} \bar{\zeta} \\
& \bar{\zeta}=-\frac{\gamma}{\lambda_{c}+r}
\end{aligned}
$$

Solving these three equations, we obtain:

$$
\begin{aligned}
& \bar{\mu}=\frac{k}{w \bar{l}\left(1-\tau_{l}\right)}-\frac{(1-\eta) \lambda_{c} \gamma}{\left(1-\tau_{l}\right)\left(\lambda_{c}+r\right)} \\
& \frac{1}{\bar{C}}=\left(1+\tau_{c}\right) \bar{\mu}+\frac{\gamma \lambda_{c} \eta}{\left(\lambda_{c}+r\right)}
\end{aligned}
$$

Using budget constraint identity evaluated at the steady state we can combine equations (A.3.23) and (A.3.24) to derive equation (65) in the text.

Taking the total derivative of (65), and recalling that $d \bar{B}=0$, we have: 


$$
N_{1} d \bar{C}=N_{2} d \gamma+N_{3} d \lambda_{c}+N_{4} d \eta
$$

where

$$
\begin{aligned}
& N_{1}=-\frac{\left(1-\tau_{l}\right)(w+r \bar{B}-\bar{C})^{2}+\left(1+\tau_{c}\right) \bar{C}^{2}}{\bar{C}^{2}\left(1-\tau_{l}\right)(w+r \bar{B}-\bar{C})^{2}}<0 \\
& N_{2}=\frac{\lambda_{c}\left[\eta\left(1-\tau_{l}\right)-(1-\eta)\left(1+\tau_{c}\right)\right]}{\left(\lambda_{c}+r\right)\left(1-\tau_{l}\right)}>;<0 \Leftrightarrow \eta>;<\frac{1+\tau_{c}}{2+\tau_{c}-\tau_{l}} \\
& N_{3}=\frac{r \gamma\left[\eta\left(1-\tau_{l}\right)-(1-\eta)\left(1+\tau_{c}\right)\right]}{\left(\lambda_{c}+r\right)^{2}\left(1-\tau_{l}\right)}>;<0 \Leftrightarrow \eta>;<\frac{1+\tau_{c}}{2+\tau_{c}-\tau_{l}} \\
& N_{4}=\frac{\lambda_{c}\left(2+\tau_{c}-\tau_{l}\right)}{\left(\lambda_{c}+r\right)\left(1-\tau_{l}\right)}>0
\end{aligned}
$$

Note that from (A.3.27) and (A.3.28):

$$
\begin{array}{lll}
\eta \downarrow 0 & \Leftrightarrow & N_{2}, N_{3}<0 \\
\eta \uparrow 1 & \Leftrightarrow & N_{2}, N_{3}>0 \\
\eta=1 / 2 & \Leftrightarrow & N_{2}, N_{3}<0
\end{array}
$$

The results shown in table 1 in the part 3 of the paper follow directly from (A.3.25)(A.3.29) for consumption, from the budget constraint identity evaluated at the steady state for leisure, and from the habits stock identity evaluated at the steady for habits.

\section{Effects of Habits Parameters on the Choice Variables Responses to Changes in the Tax Policy.}

By (A.3.25)-(A3.29):

$$
\frac{d \bar{C}}{d \gamma}=\frac{N_{2}}{N_{1}}=-\frac{\lambda_{c}\left[\eta\left(1-\tau_{l}\right)-(1-\eta)\left(1+\tau_{c}\right)\right] \bar{C}^{2}(w-\bar{C}+r \bar{B})^{2}}{\left(\lambda_{c}+r\right)\left[\left(1-\tau_{l}\right)(w-\bar{C}+r \bar{B})^{2}+\left(1+\tau_{c}\right) \bar{C}^{2}\right]}
$$

Equation (A.3.31) implies that

$$
Q_{1} \frac{d^{2} \bar{C}}{d \tau_{c} d \gamma}=Q_{2}-Q_{3} \frac{d \bar{C}}{d \tau_{c}}>0
$$

where 


$$
\begin{aligned}
Q_{1}= & {\left[\frac{\lambda_{c} \bar{C}^{2} w \bar{l}}{\left(\lambda_{c}+r\right)\left[\left(1-\tau_{l}\right) w^{2} \bar{l}^{2}+\left(1+\tau_{c}\right) \bar{C}^{2}\right]}\right]^{-1}>0 } \\
Q_{2} & =w \bar{l}\left[(1-\eta)\left(1-\tau_{l}\right) w^{2} \bar{l}^{2}+\eta\left(1-\tau_{l}\right) \bar{C}^{2}\right]>0 \\
Q_{3}= & 2\left[\eta\left(1-\tau_{l}\right)-(1-\eta)\left(1+\tau_{c}\right)\right] \times \\
& \times \frac{\left(1-\tau_{l}\right) w^{3} \bar{l}^{3}-\left(1-\tau_{l}\right) w^{2} \bar{l}^{2}-\left(1+\tau_{c}\right) \bar{C}^{2}+\bar{C} w^{2} \bar{l}^{2}\left(1-\tau_{l}\right)}{\left[\left(1-\tau_{l}\right) w^{2} \bar{l}^{2}+\left(1+\tau_{c}\right) \bar{C}^{2}\right]^{2}}>;<0
\end{aligned}
$$

Set $\tau_{l}=0$ for simplicity and evaluate:

$$
\begin{aligned}
& \frac{\left(\lambda_{c}+r\right)\left[w^{2} \bar{l}^{2}+\left(1+\tau_{c}\right) \bar{C}^{2}\right]}{\lambda_{c} \bar{C}^{2} w \bar{l}} \frac{d^{2} \bar{C}}{d \tau_{c} d \gamma}= \\
& =w \bar{l}\left[(1-\eta) w^{2} \bar{l}^{2}+\eta \bar{C}^{2}\right]+2\left[\eta-(1-\eta)\left(1+\tau_{c}\right)\right] \frac{d \bar{C}}{d \tau_{c}} \times \\
& \times \frac{w^{3} \bar{l}^{3}-w^{2} \bar{l}^{2}-\left(1+\tau_{c}\right) \bar{C}^{2}+w^{2} \bar{l}^{2} \bar{C}}{\left[w^{2} \bar{l}^{2}+\left(1+\tau_{c}\right) \bar{C}^{2}\right]^{2}}
\end{aligned}
$$

The difficulty of signing (A.3.36) arises since

$$
w^{3} \bar{l}^{3}+w^{2} \bar{l}^{2} \bar{C}>;<w^{2} \bar{l}^{2}+\left(1+\tau_{c}\right) \bar{C}^{2}
$$

For the households with sufficiently high consumption and relatively low leisure expenditure, the right-hand side term in (A.3.36) dominates the left-hand side.

Since $d \bar{C} / d \tau_{c}$ is negative, this implies that whenever the term $\left[\eta-(1-\eta)\left(1+\tau_{c}\right)\right]<0$, the overall effect of the strength of habits parameter on consumption response to changes in the consumption tax will be positive. In case, when $\left[\eta-(1-\eta)\left(1+\tau_{c}\right)\right]>0$ the effect is not determined ex ante. Note that in table 1 in part 3 we present this boundary in terms of $\eta>\frac{1+\tau_{c}}{2-\tau_{l}+\tau_{c}}$ 
Alternatively, when households engage in low consumption and high leisure expenditure, the left-hand side of the above inequality dominates the right-hand side, so that the above conditions are reversed. Table 1 and discussion below assumes the former case over the latter. This assumption is warranted by the empirical observations that within overall household budgets, consumption clearly dominates leisure expenditure. However, the converse assumption can also be used in the context of this model.

We now proceed to illustrate these results by taking three extreme choice of values for $\eta$.

For $\eta \downarrow 0$ :

$$
\frac{\left(\lambda_{c}+r\right)\left[w^{2} \bar{l}^{2}+\left(1+\tau_{c}\right) \bar{C}^{2}\right]}{\lambda_{c} w^{2} \bar{l}^{2} \bar{C}^{2}} \frac{d^{2} \bar{C}}{d \tau_{c} d \gamma}=w^{2} \bar{l}^{2}>0
$$

And the overall result is uncertain.

For $\eta \uparrow 1$ :

$$
\frac{\left(\lambda_{c}+r\right)\left[w^{2} \bar{l}^{2}+\left(1+\tau_{c}\right) \bar{C}^{2}\right]}{\lambda_{c} \bar{C}^{2} w^{2} \bar{l}^{2}} \frac{d^{2} \bar{C}}{d \tau_{c} d \gamma}=\bar{C}^{2}>0
$$

For $\eta=1 / 2$ :

$$
\begin{aligned}
& \frac{\left(\lambda_{c}+r\right)\left[w^{2} \bar{l}^{2}+\left(1+\tau_{c}\right) \bar{C}^{2}\right]}{\lambda_{c} \bar{C}^{2} w \bar{l}} \frac{d^{2} \bar{C}}{d \tau_{c} d \gamma}= \\
& =\frac{1}{2} w \bar{l}\left[w^{2} \bar{l}^{2}+\bar{C}^{2}\right]- \\
& -\tau_{c} \frac{d \bar{C}}{d \tau_{c}} \frac{\{(w \bar{l}-1)\}\left[w^{2} \bar{l}^{2}+\left(1+\tau_{c}\right) \bar{C}^{2}\right]+w \bar{l}\left\{\bar{C}\left(1+\tau_{c}\right)-w \bar{l}\right\}}{\left[w^{2} \bar{l}^{2}+\left(1+\tau_{c}\right) \bar{C}^{2}\right]^{2}}>0
\end{aligned}
$$

Next we analyse the effects of the speed of habits stock adjustment to the steady state, $\lambda_{c}$.

By (A.3.25)-(A.3.29): 


$$
\frac{d \bar{C}}{d \lambda_{c}}=-\frac{\bar{C}^{2}(w+r \bar{B}-\bar{C})^{2} r \gamma\left[\eta\left(1-\tau_{l}\right)-(1-\eta)\left(1+\tau_{c}\right)\right]}{\left(\lambda_{c}+r\right)^{2}\left[\left(1-\tau_{l}\right)(w+r \bar{B}-\bar{C})^{2}+\left(1+\tau_{c}\right) \bar{C}^{2}\right]}
$$

so that

$$
\begin{gathered}
\frac{\left(\lambda_{c}+r\right)^{2}\left[\left(1-\tau_{l}\right) w^{2} \bar{l}^{2}+\left(1+\tau_{c}\right) \bar{C}^{2}\right]}{r \gamma\left[\eta\left(1-\tau_{l}\right)-(1-\eta)\left(1+\tau_{c}\right)\right] w \bar{l}} \frac{d^{2} \bar{C}}{d \lambda_{c} d \tau_{c}}=\bar{C}^{2} w \bar{l}(1-\eta)+ \\
+2 \frac{\left(1-\tau_{l}\right) w^{2} \bar{l}^{2}\left(1+\bar{C}^{2}-w \bar{l} \bar{C}\right)+\left(1+\tau_{c}\right) \bar{C}^{2}}{\left[\left(1-\tau_{l}\right) w^{2} \bar{l}^{2}+\left(1+\tau_{c}\right) \bar{C}^{2}\right]} \frac{(-)}{d \bar{C}}
\end{gathered}
$$

As above, let $\tau_{l}=0$ for simplicity and evaluate:

$$
\begin{aligned}
& \underbrace{\frac{\left(\lambda_{c}+r\right)^{2}\left[w^{2} \bar{l}^{2}+\left(1+\tau_{c}\right) \bar{C}^{2}\right]}{r \gamma\left[\eta-(1-\eta)\left(1+\tau_{c}\right)\right] w \bar{l}} \frac{d^{2} \bar{C}}{d \lambda_{c} d \tau_{c}}}_{\begin{array}{c}
(+) i f f \eta>\frac{1+\tau_{c}}{2-\tau_{l}+\tau_{c}} \\
(-) i f f \eta<\frac{1+\tau_{c}}{2-\tau_{l}+\tau_{c}}
\end{array}}= \\
& =\overbrace{\bar{C}^{2} w \bar{l}(1-\eta)+\overbrace{w^{2} \bar{l}^{2}\left(1+\bar{C}^{2}-w \overline{l C}\right)+\left(1+\tau_{c}\right) \bar{C}^{2}}^{(+)}}^{\frac{(-)}{d \bar{C}}} \frac{\left.d w^{2} \bar{l}^{2}+\left(1+\tau_{c}\right) \bar{C}^{2}\right]}{d \tau_{c}}>0
\end{aligned}
$$

Hence, by definition of $\frac{d \bar{C}}{d \tau_{c}}$ :

$$
\frac{d^{2} \bar{C}}{d \lambda_{c} d \tau_{c}}>0 \text { iff } \eta<\frac{1+\tau_{c}}{2-\tau_{l}+\tau_{c}}
$$

In the case of $\eta \downarrow 0$ :

$$
\frac{\left(\lambda_{c}+r\right)^{2}}{r \gamma w \bar{l}\left(1+\tau_{c}\right)} \frac{d^{2} \bar{C}}{d \lambda_{c} d \tau_{c}}=\frac{\bar{C}^{2} w \bar{l}}{\left[w^{2} \bar{l}^{2}+\left(1+\tau_{c}\right) \bar{C}^{2}\right]}>0
$$

68 
For $\eta \uparrow 1$

$\frac{d^{2} \bar{C}}{d \lambda_{c} d \tau_{c}}=0$

Finally, for $\eta=1 / 2$, since

$$
\frac{d \bar{C}}{d \tau_{c}}=-\frac{\bar{C} l\left(\lambda_{c}+r+\frac{\gamma \lambda_{c} \bar{C}}{2}\right)}{\left(1+\tau_{c}\right)\left(\lambda_{c}+r\right) w\left[w^{2} k \bar{C}^{2}+w^{2} \bar{l}^{2}\right]}<0,
$$

then

$$
\begin{aligned}
& \frac{4\left(\lambda_{c}+r\right)^{2}}{r \gamma w \bar{l} \tau_{c} \overline{C l}} \frac{d^{2} \bar{C}}{d \lambda_{c} d \tau_{c}}=\frac{2 \bar{C} w}{\left[w^{2} \bar{l}^{2}+\left(1+\tau_{c}\right) \bar{C}^{2}\right]}- \\
& -\frac{(+)}{\overbrace{\left[w^{2} \bar{l}^{2}\left(1+\bar{C}^{2}-w \overline{l C}\right)+\left(1+\tau_{c}\right) \bar{C}^{2}\right]\left(2 \lambda_{c}+2 r+\gamma \lambda_{c} \bar{C}\right)}^{\left(1+\tau_{c}\right)\left(\lambda_{c}+r\right) w\left[w^{2} k \bar{C}^{2}+w^{2} \bar{l}^{2}\right]\left[w^{2} \bar{l}^{2}+\left(1+\tau_{c}\right) \bar{C}^{2}\right]^{2}}}>;<0
\end{aligned}
$$

For the effect of $\eta$ :

$$
\frac{d \bar{C}}{d \eta}=\frac{N_{4}}{N_{1}}=-\frac{\lambda_{c}\left(2+\tau_{c}-\tau_{l}\right) \bar{C}^{2}(w+r \bar{B}-\bar{C})^{2}}{\left(\lambda_{c}+r\right)\left[\left(1-\tau_{l}\right)(w+r \bar{B}-\bar{C})^{2}+\left(1+\tau_{c}\right) \bar{C}^{2}\right]}
$$

Hence, by definition of $\frac{d \bar{C}}{d \tau_{c}}$ in (A.3.16) and (A.3.17):

$$
\begin{gathered}
\frac{\left(\lambda_{c}+r\right)\left[w^{2} \bar{l}^{2}+\left(1+\tau_{c}\right) \bar{C}^{2}\right]^{2}}{\lambda_{c} \bar{C} w \bar{l}} \frac{d^{2} \bar{C}}{d \tau_{c} d \eta}=-\bar{C} w \bar{l}\left[w^{2} \bar{l}^{2}-\bar{C}^{2}\left(1+\tau_{c}\right)\right]- \\
-\left(2+\tau_{c}\right) 2 \frac{d \bar{C}}{d \tau_{c}}\left[w^{3} \bar{l}^{3}-\left(1+\tau_{c}\right) \bar{C}^{3}\right]>;<0
\end{gathered}
$$

For the case of labour income tax, setting $\tau_{c}=0$, by (A.3.31): 


$$
\begin{aligned}
& \frac{\left[\left(1-\tau_{l}\right) w^{2} \bar{l}^{2}+\bar{C}^{2}\right]^{2}\left(\lambda_{c}+r\right)}{\lambda_{c} \bar{C} w \bar{l}} \frac{d^{2} \bar{C}}{d \gamma d \tau_{l}}=\left(\eta \bar{C}^{2}+(1-\eta) w^{2} \bar{l}^{2}\right) \bar{C} w \bar{l}- \\
& -2 \underbrace{\left[\eta\left(1-\tau_{l}\right)-(1-\eta)\right]}_{(+l-)} \underbrace{\left\{\left(1-\tau_{l}\right) w^{3} \bar{l}^{3}-\bar{C}^{3}\right\}}_{(-)} \frac{d \bar{C}}{d \tau_{l}}
\end{aligned}
$$

Hence, if $\eta<1 /\left(2-\tau_{l}\right)$, then $\frac{d^{2} \bar{C}}{d \gamma d \tau_{l}}>0$.

The rest of Table 1 results follow along the same lines.

Finally, for the relative effects of $\gamma$ and other habits parameters:

$$
\begin{aligned}
& \frac{\bar{C}\left[\left(1-\tau_{l}\right) w^{2} \bar{l}^{2}+\bar{C}^{2}\right]^{2}}{\left[w^{2} \bar{l}^{2}+\left(1+\tau_{c}\right) \bar{C}^{2}\right]} \frac{d^{2} \bar{C}}{d \gamma d \tau_{l}} / \frac{d^{2} \bar{C}}{d \tau_{c} d \gamma}= \\
& \left(\eta \bar{C}^{2}+(1-\eta) w^{2} \bar{l}^{2}\right) \bar{C} w \bar{l}-2 \underbrace{\left[\eta\left(1-\tau_{l}\right)-(1-\eta)\right]}_{(+/-)} \underbrace{\left\{\left(1-\tau_{l}\right) w^{3} \bar{l}^{3}-\bar{C}^{3}\right\}}_{(-)} \frac{d \bar{C}}{d \tau} \\
& w \bar{l}\left[(1-\eta) w^{2} \bar{l}^{2}+\eta \bar{C}^{2}\right]+2 \underbrace{\left[\eta-(1-\eta)\left(1+\tau_{c}\right)\right]}_{(+/-)} \frac{d \bar{C}}{d \tau} \underbrace{\frac{w^{3} \bar{l}^{3}-w^{2} \bar{l}^{2}-\left(1+\tau_{c}\right) \bar{C}^{2}+w^{2} \bar{l}^{2} \bar{C}}{\left[w^{2} \bar{l}^{2}+\left(1+\tau_{c}\right) \bar{C}^{2}\right]^{2}}}_{c}
\end{aligned}
$$

For the sake of comparison, set $\tau_{c}=\tau_{l}$ so that consumption tax is numerically equivalent to the leisure tax. Then the above conditions in equation (A.3.46) imply:

$$
\begin{array}{lll}
\eta(1-\tau)-(1-\eta)>;<0 & \Leftrightarrow & \eta>;<1 /(2-\tau) \\
\eta-(1-\eta)(1+\tau)>;<0 & \Leftrightarrow & \eta>;<(1+\tau) /(2+\tau)
\end{array}
$$

Further, suppose the $w \bar{l}=a \bar{C}$, while $\bar{B}=0$ so that equation (A.3.46) itself becomes 


$$
\begin{aligned}
& \frac{\left[(1-\tau) a^{2}+1\right]^{2}}{\left[a^{2}+1+\tau\right]} \frac{d^{2} \bar{C}}{d \gamma d \tau_{l}} / \frac{d^{2} \bar{C}}{d \tau \tau_{c} d \gamma}= \\
& a \bar{C}\left(\eta+(1-\eta) a^{2}\right)-2[\underbrace{[\eta(2-\tau)-1]}_{(+l-)} \underbrace{\left\{(1-\tau) a^{3}-1\right\}}_{(-)} \frac{d \bar{C}}{d \tau_{l}} \\
& \frac{a \bar{C}^{3}\left[(1-\eta) a^{2}+\eta\right]+2[\underbrace{[\eta-(1-\eta)(1+\tau)]}_{(+/-)} \frac{d \bar{C}}{d \tau_{c}} \underbrace{a^{3} \bar{C}-a^{2}-(1+\tau)+a^{2} \bar{C}}_{(+-)}}{\left[a^{2}+1+\tau\right]^{2} \bar{C}^{2}}
\end{aligned}
$$

This remains no more tractable than equation (A.3.46). Hence, we return to the original equation: set $\eta=0$ :

$$
\frac{d^{2} \bar{C}}{d \gamma d \tau_{l}} / \frac{d^{2} \bar{C}}{d \tau_{c} d \gamma}=\frac{\left[w^{2} \bar{l}^{2}+(1+\tau) \bar{C}^{2}\right]}{\left[(1-\tau) w^{2} \bar{l}^{2}+\bar{C}^{2}\right]^{2}}<1
$$

since

$$
w^{2} \bar{l}^{2}+\left(1+\tau_{c}\right) \bar{C}^{2}<\left[\left(1-\tau_{l}\right) w^{2} \bar{l}^{2}+\bar{C}^{2}\right]^{2}
$$

The same applies to the case of $\eta=1$.

For $\eta=1 / 2$ :

$$
\begin{aligned}
& \frac{\bar{C}\left[(1-\tau) w^{2} \bar{l}^{2}+\bar{C}^{2}\right]^{2}}{\left[w^{2} \bar{l}^{2}+(1+\tau) \bar{C}^{2}\right]} \frac{d^{2} \bar{C}}{d \gamma d \tau} / \frac{d^{2} \bar{C}}{d \tau d \gamma}= \\
& \left(\bar{C}^{2}+w^{2} \bar{l}^{2}\right) \bar{C} w \bar{l}+2 \tau l \underbrace{\left\{(1-\tau) w^{3} \bar{l}^{3}-\bar{C}^{3}\right\}} \frac{d \bar{C}}{d \tau}
\end{aligned}
$$

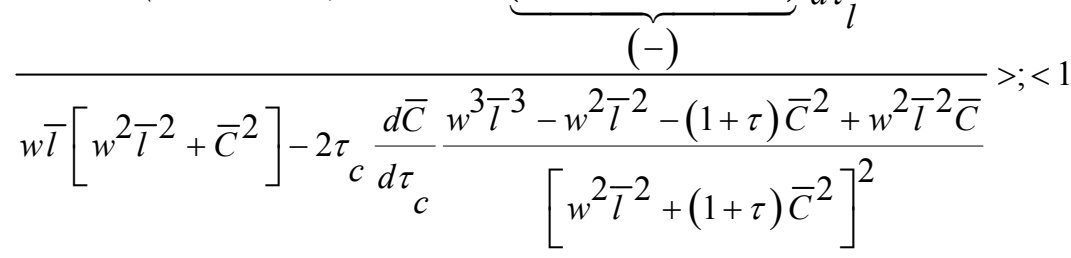

By (A.3.14) for $\eta=1 / 2$ :

$$
\frac{d \bar{C}}{d \tau_{l}}=-\frac{w \bar{l}}{k\left(1-\tau_{l}\right)}\left[\frac{k 2\left(\lambda_{c}+r\right)-\bar{l} \lambda_{c} \gamma w}{2\left(\lambda_{c}+r\right)}\right]
$$

Then by the above and (A.3.41) 


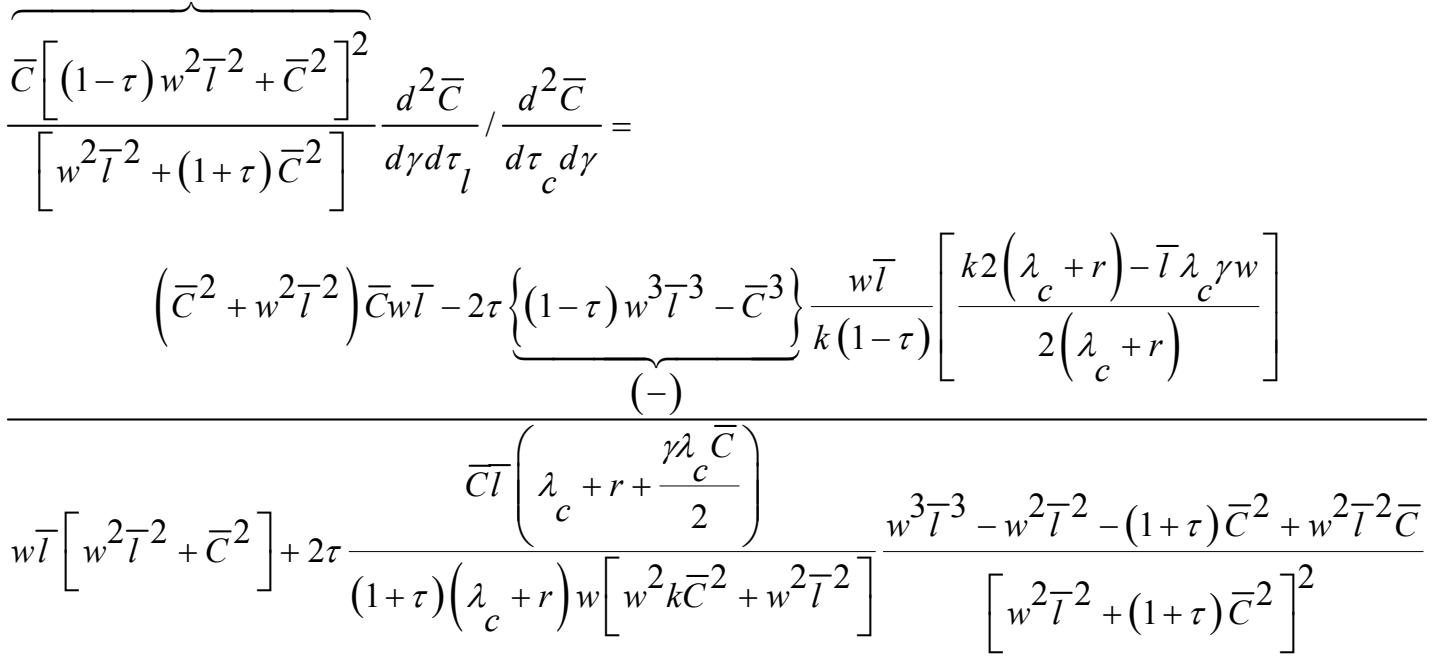

Assume $\tau_{c}=\tau_{l} \approx 0$

$\frac{d^{2} \bar{C}}{d \gamma d \tau_{l}} / \frac{d^{2} \bar{C}}{d \tau_{c} d \gamma}=1$

Hence, no cross comparisons outside the limit points for the value of $\eta$ is possible.

Furthermore, from equation (A.3.45) and conditions (A.3.46) it is clear that overall relative effect of $\gamma$ on the responses of consumption to changes in tax rates will depend on the importance of consumption in habits stock law of motion, $\eta$, and on the size of consumption expenditure relative to the size of leisure expenditure by the households. 
Figure 1. Dynamic Adjustments in Model 1. Case A: $-\phi>\lambda$
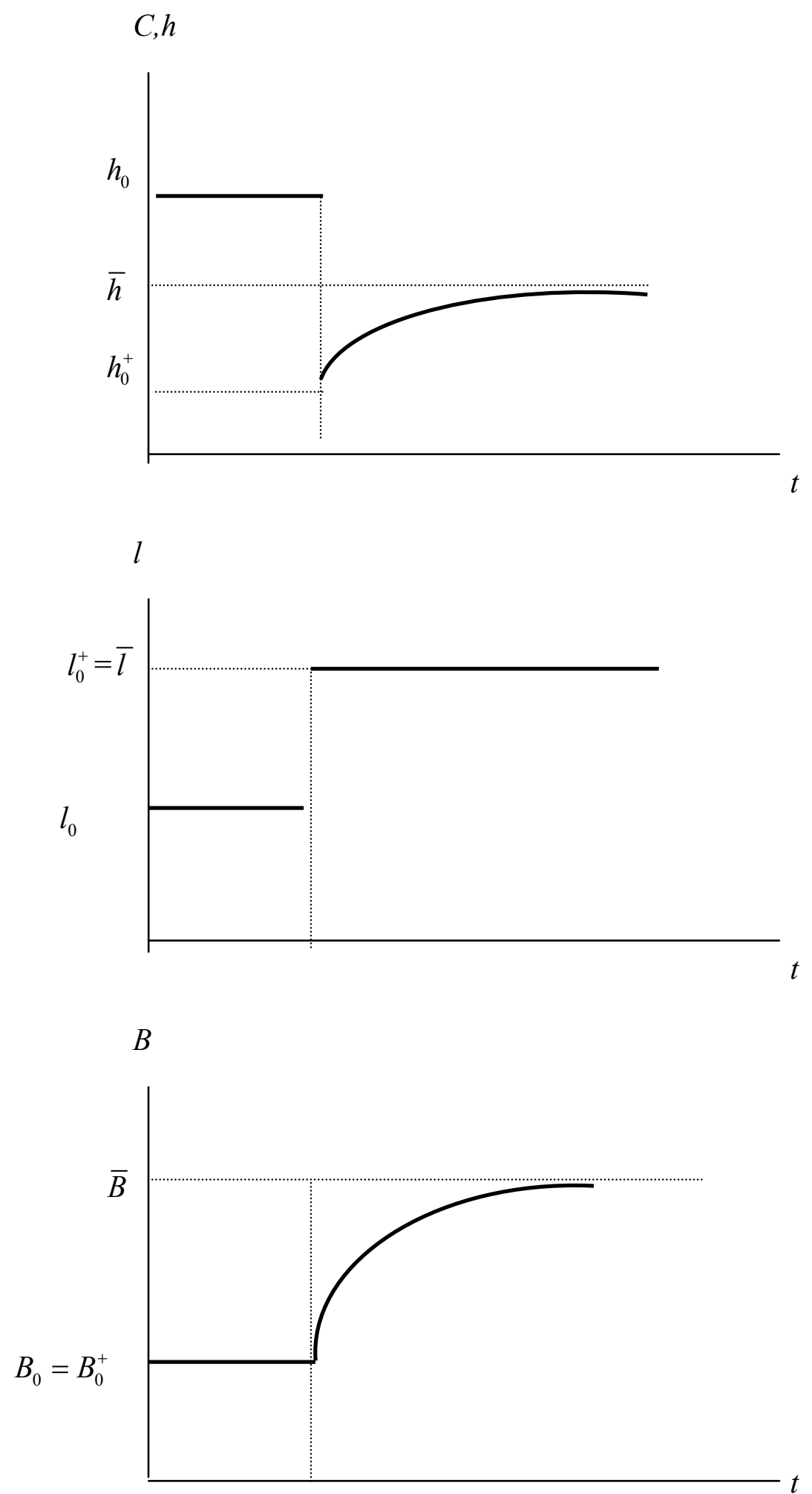
Figure 2. Dynamic Adjustments in Model 1. Case B: $-\phi<\lambda$
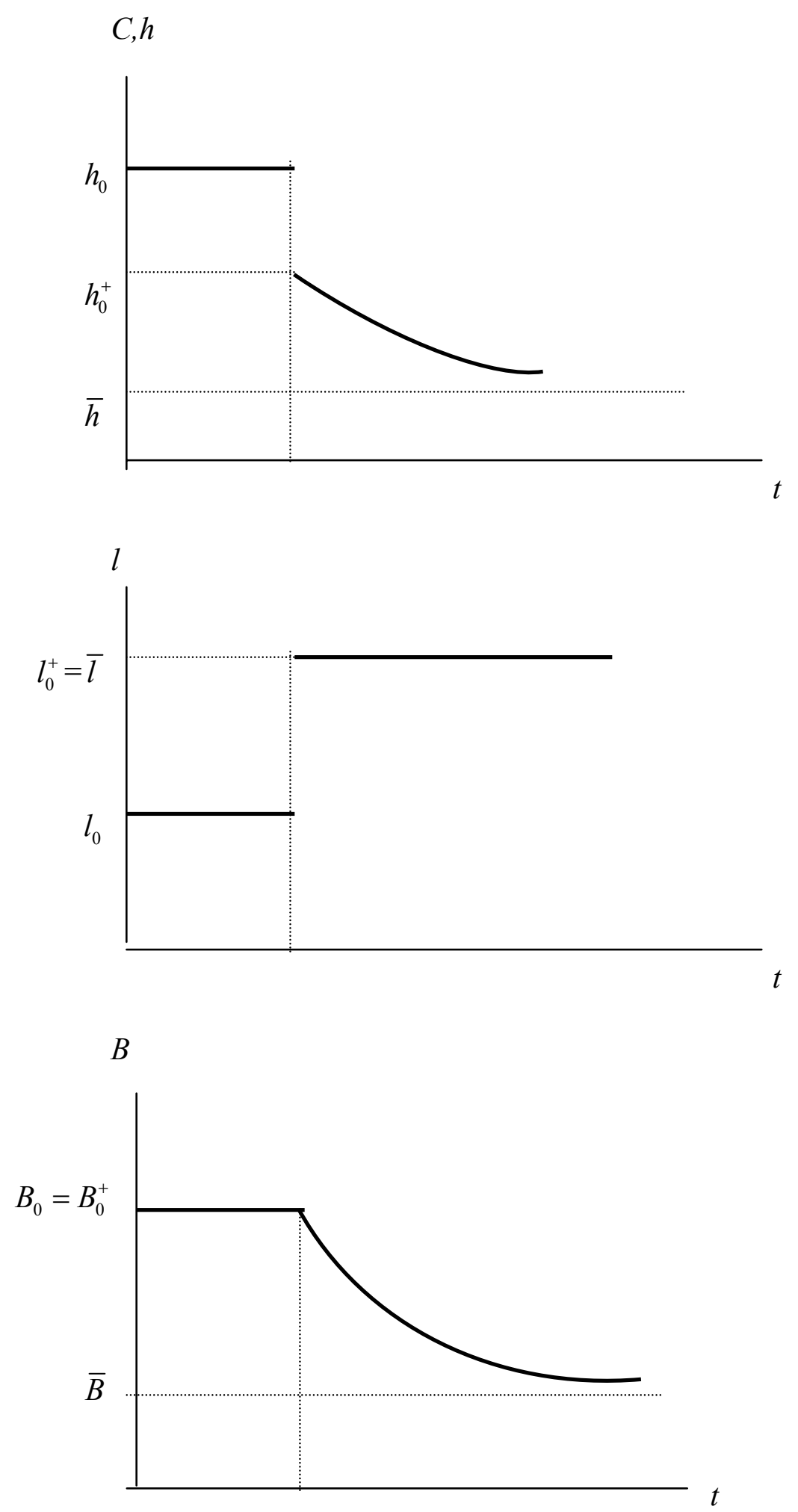
Figure 3. Dynamic Adjustments in Model 2. Case A: $-\phi_{c}<\lambda_{c}$. Change in the Labour Income Tax.
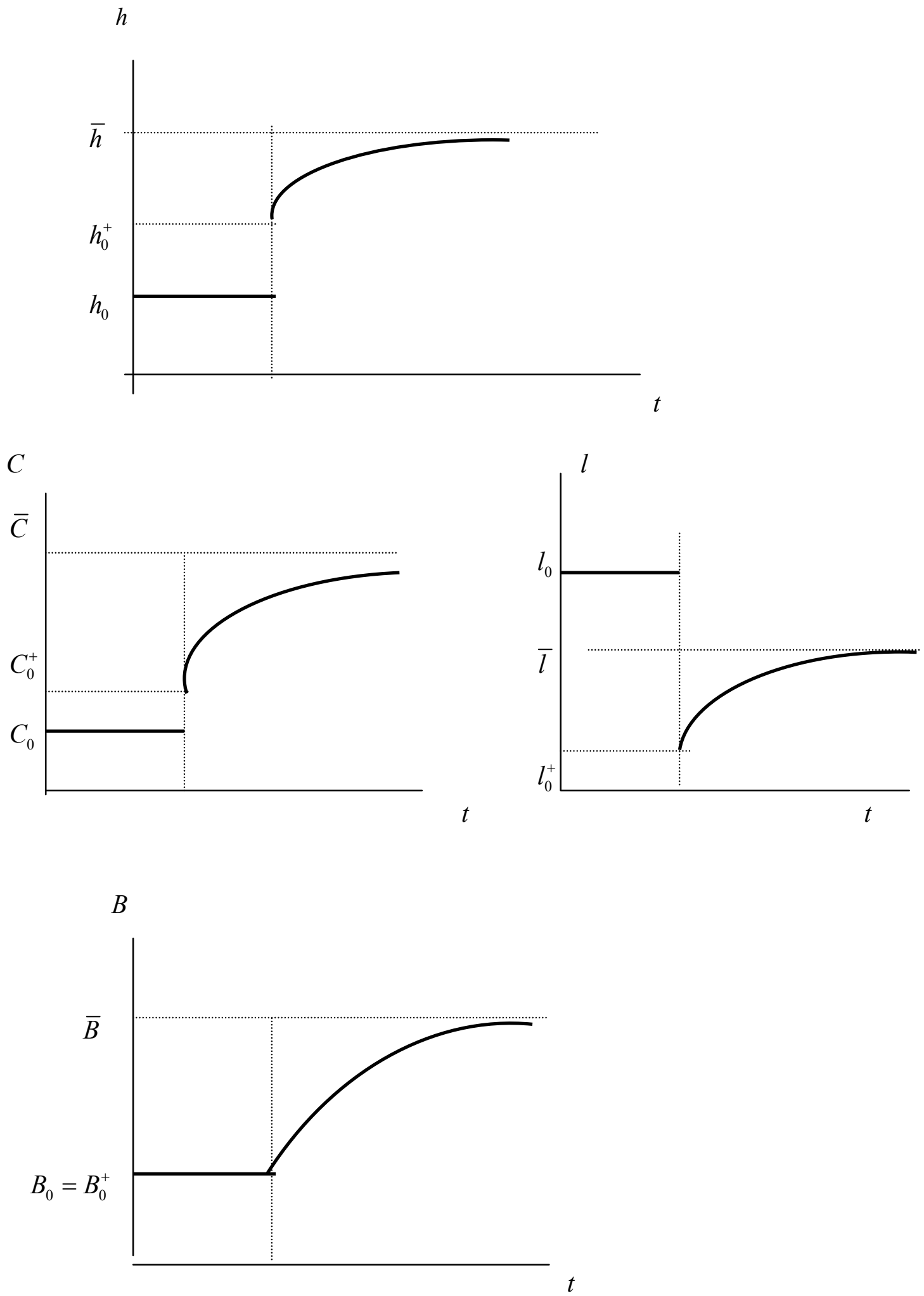
Figure 4. Dynamic Adjustments in Model 2. Case B: $\lambda_{c}<-\phi_{c}$. Change in the Labour Income Tax.
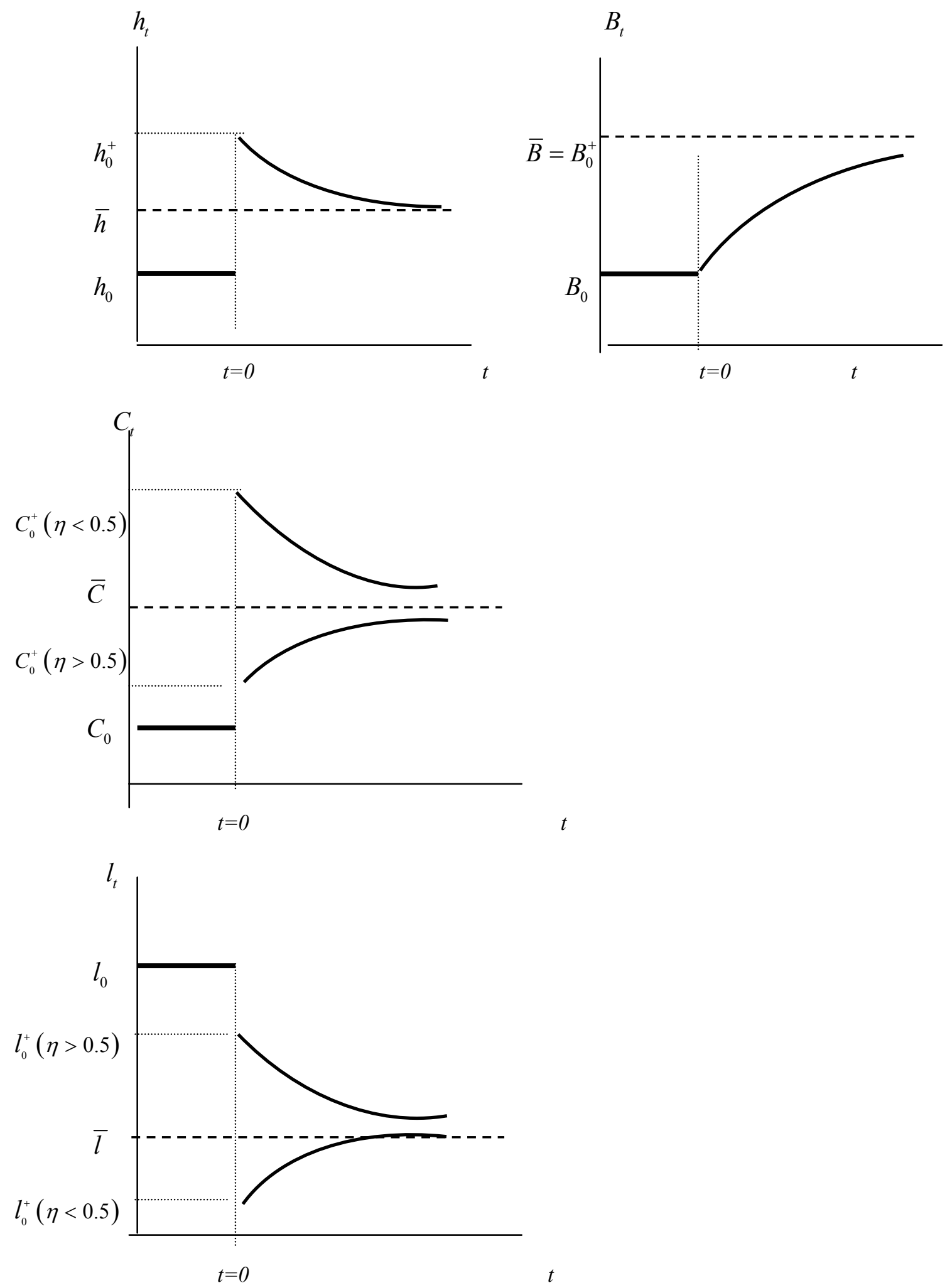
Figure 5. Dynamic Adjustments in Model 2. Case C: $\lambda_{c}<-\phi_{c}$. Change in the Labour Income Tax.
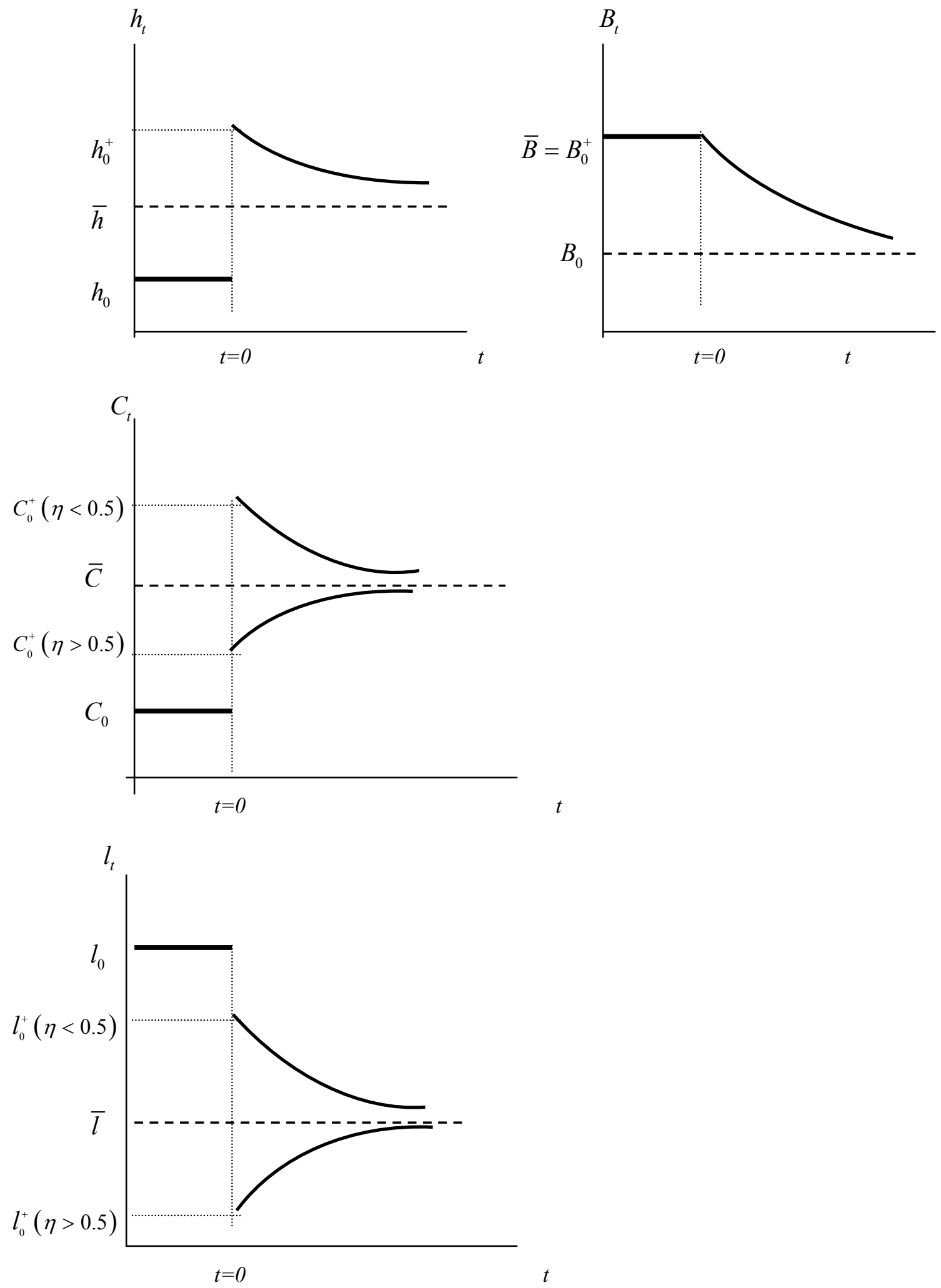
Figure 6. Dynamic Adjustments in Model 2. Case A: $-\phi_{c}<\lambda_{c}$. Change in the Consumption Tax.

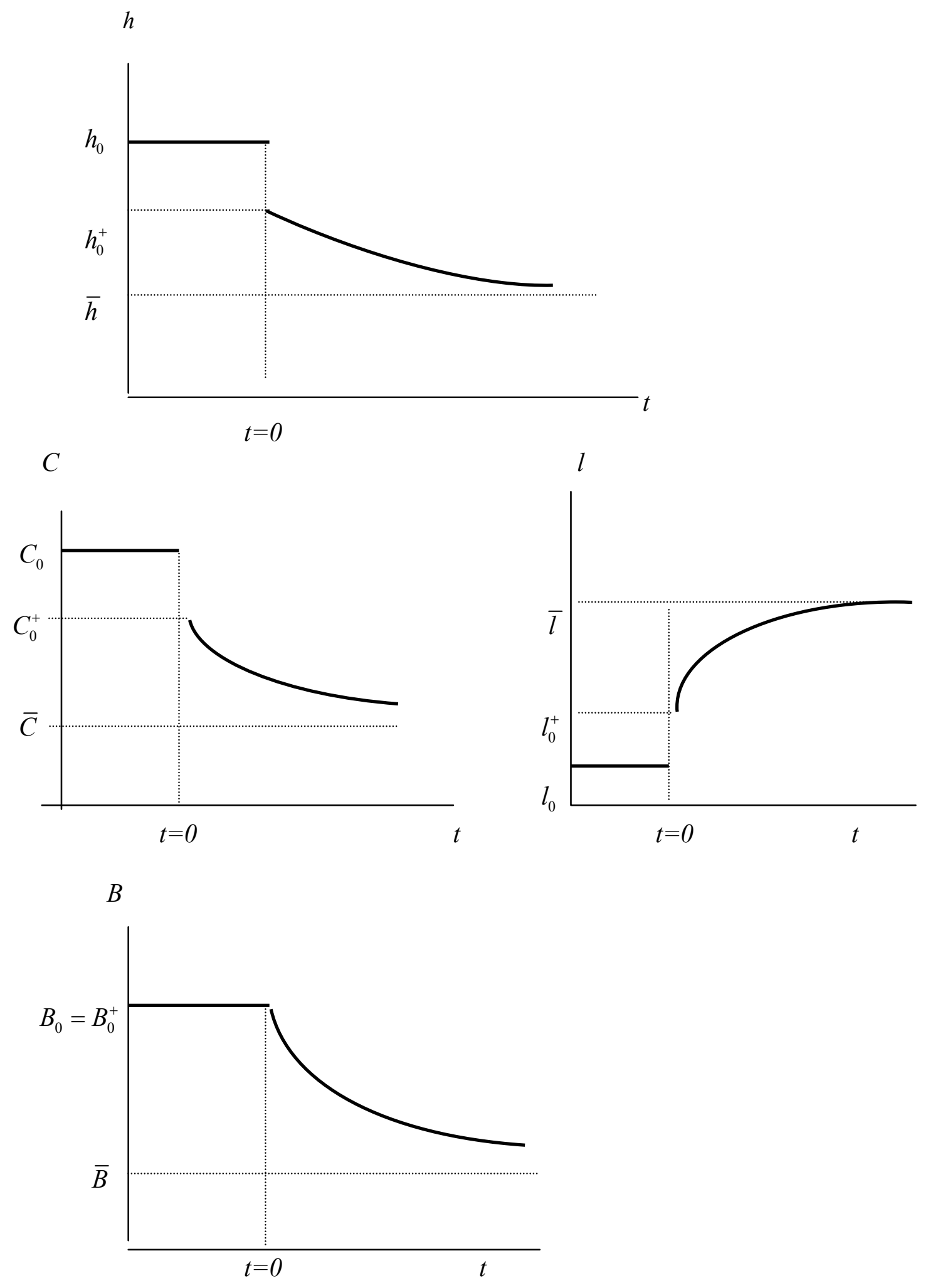


Figure 7. Dynamic Adjustments in Model 2. Case B: $\lambda_{c}<-\phi_{c}$. Change in the Consumption Tax.
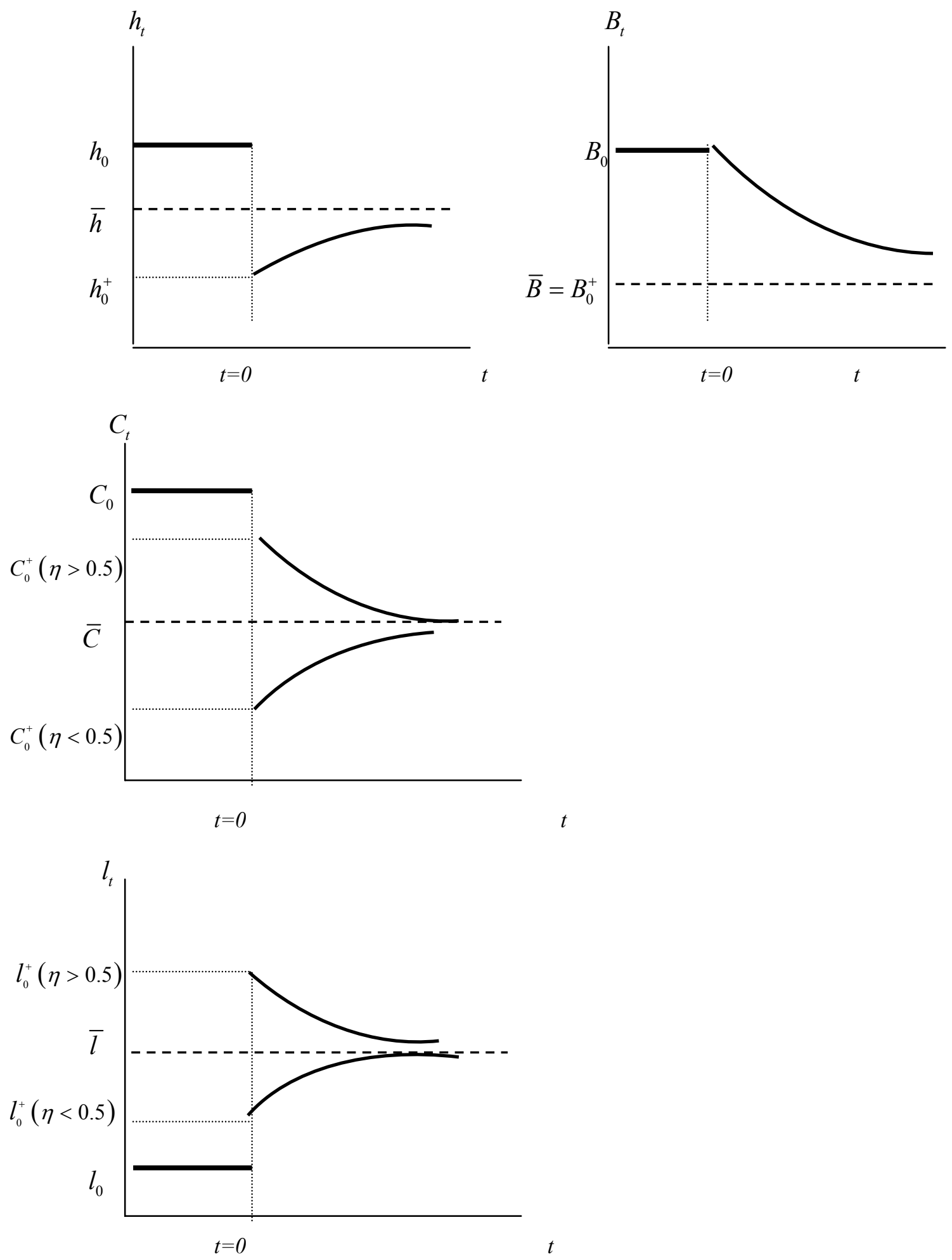
Figure 8. Dynamic Adjustments in Model 2. Case C: $\lambda_{c}<-\phi_{c}$. Change in the Consumption Tax.
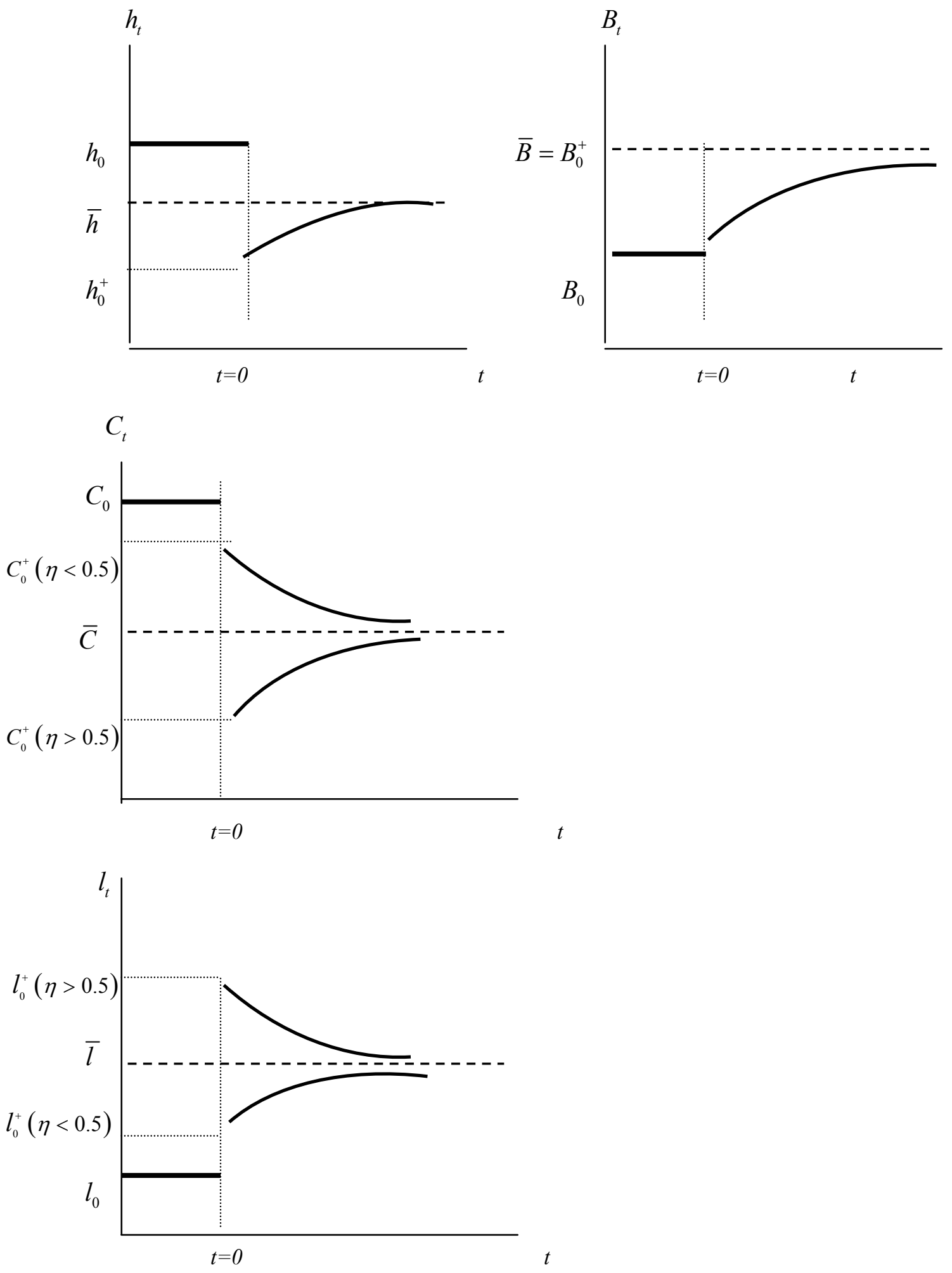
Figure 9. Dynamic Adjustments in Model 3: Specific Utility Function. Change in the Consumption Tax.

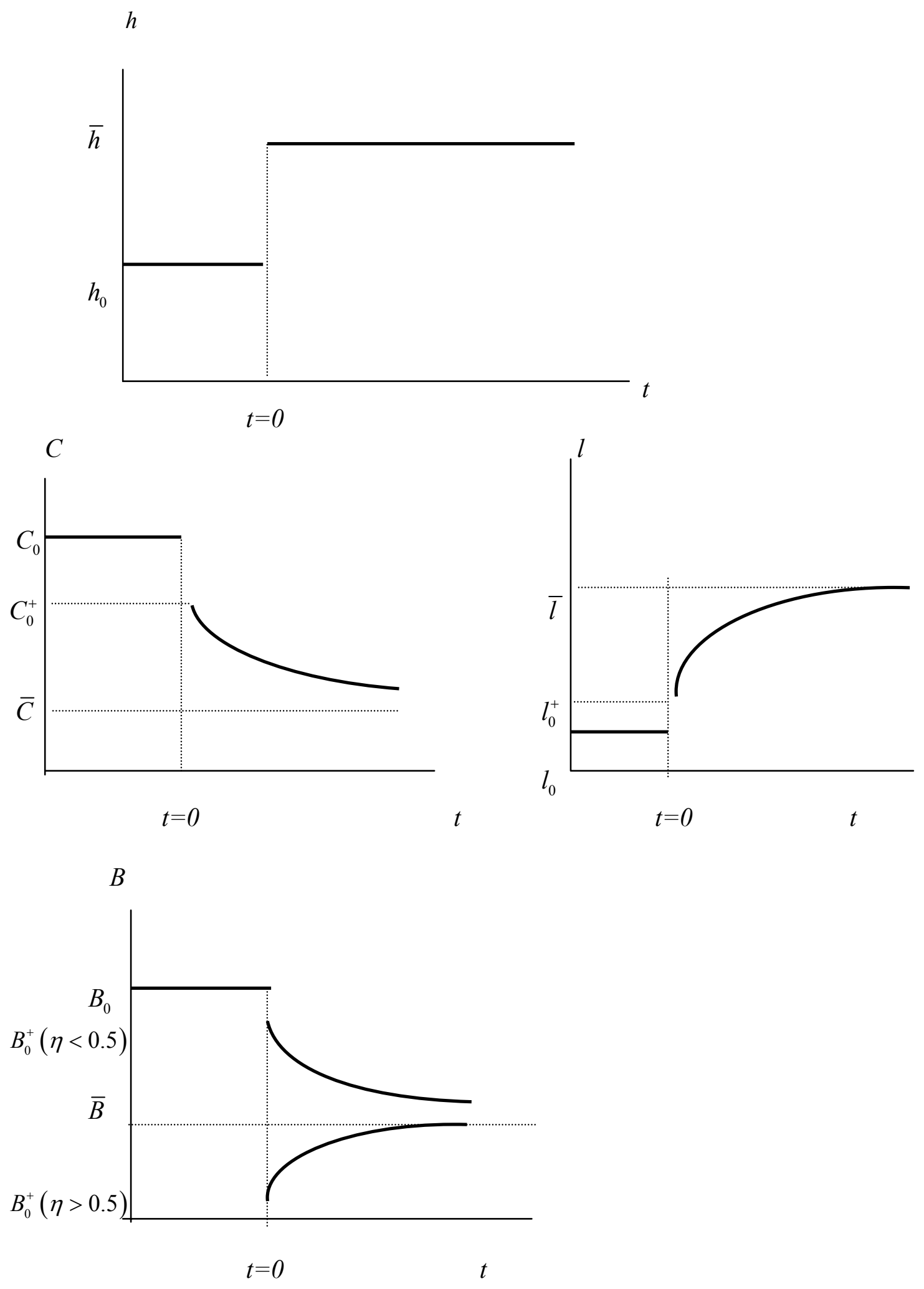

